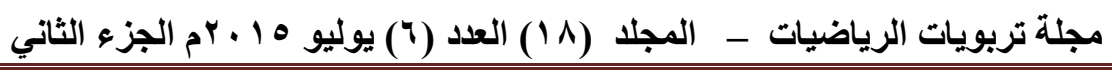

أثر استفدام استراتيجية التدريس التبادلي في خفض هستوى قلق

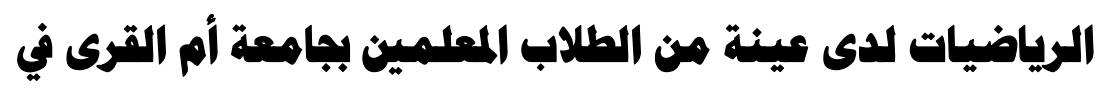

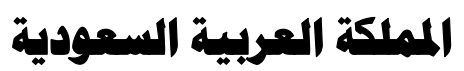

$$
\text { د. يحيى مزهر عطية الزهر اني }
$$

أستاذ المناهج وطرق تدريس الرياضيات المساعد

$$
\text { بجامعة أم القرى- مكة المكرمة }
$$




\section{(ملخص الدراسة):}

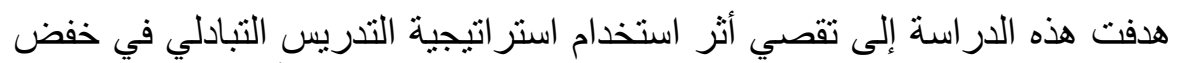

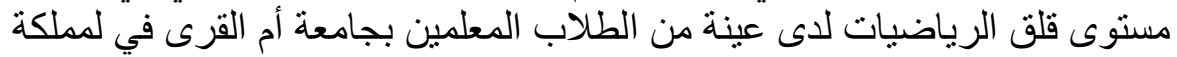

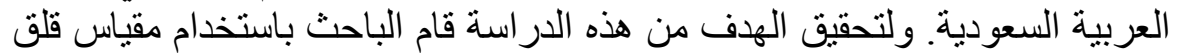

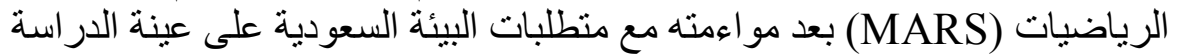

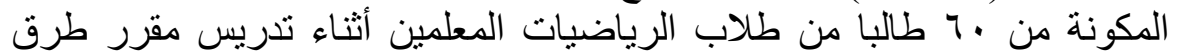

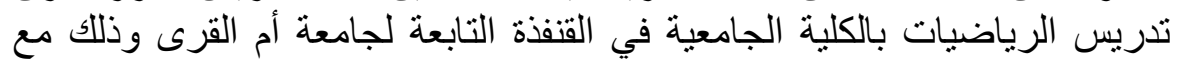

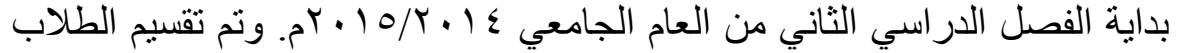

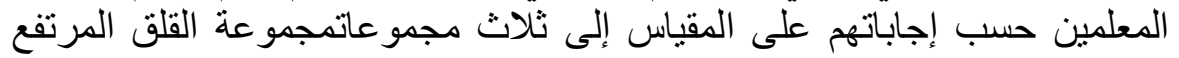

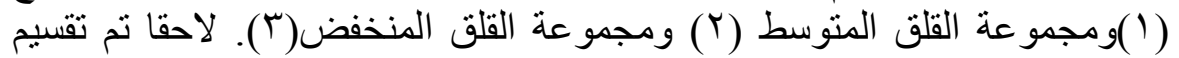

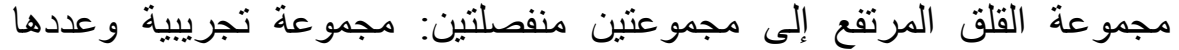

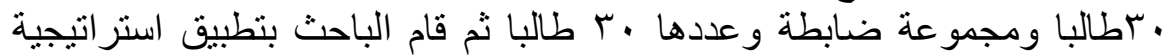

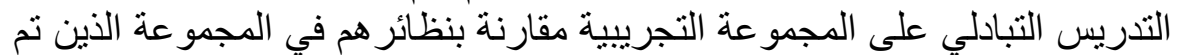

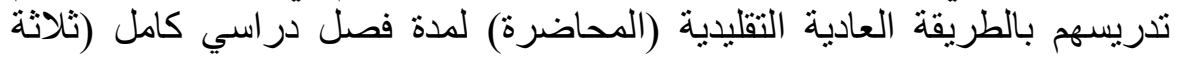
أشهر تقريبا). تم إعادة تطبيق مقياس قلق الرية الرياضيات على على جميع أفراد العينة

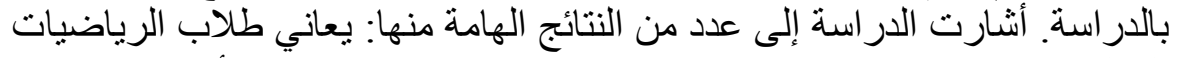

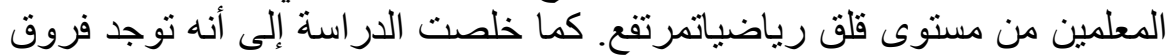

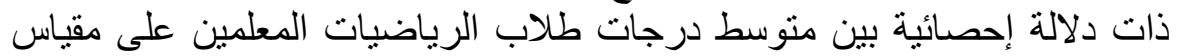

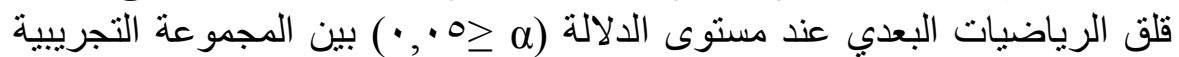

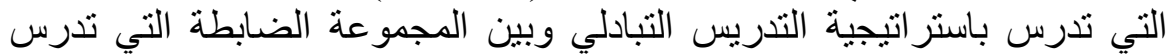

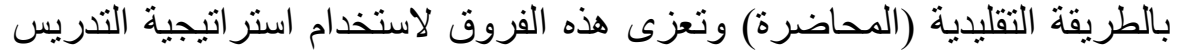

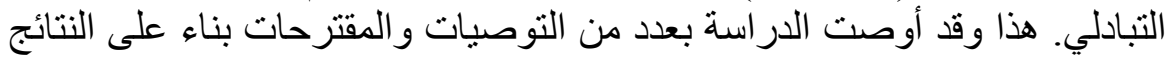

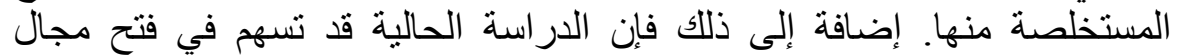

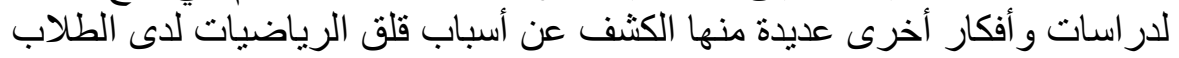

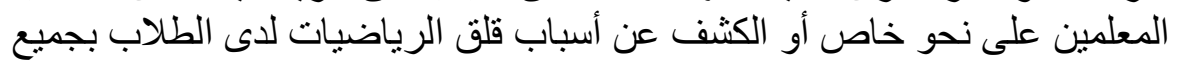

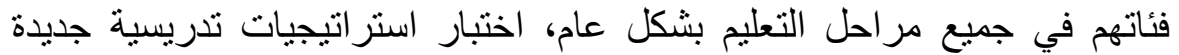

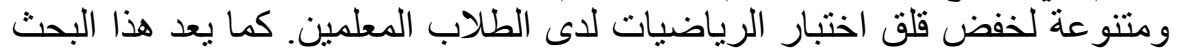

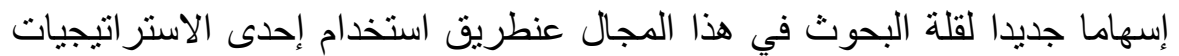

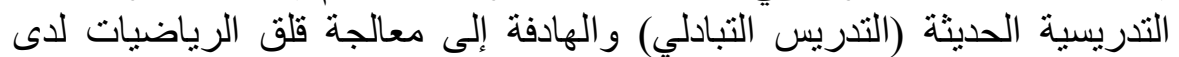

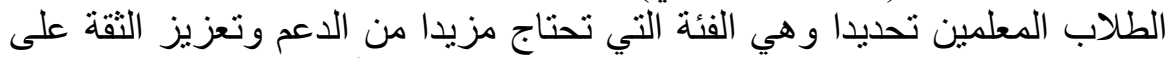

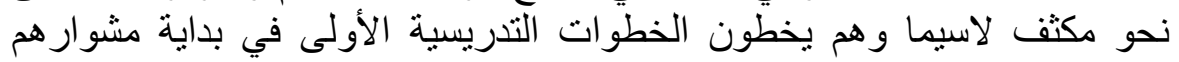




\section{المقدمة:}

يشهر قطاع التعليم حر اكأ مختلفأ ودائما من خلال الأبحاث العلمية الساعية

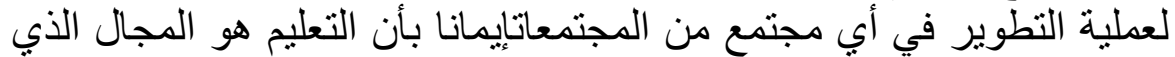

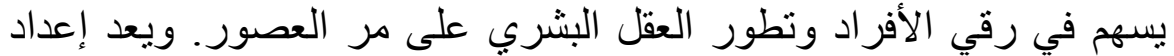

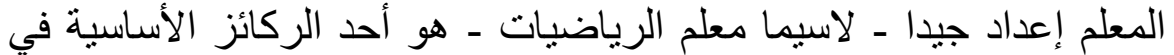

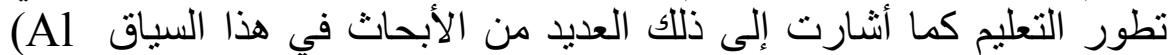
Zahrani, 2014, Bakare, 2011, Tatto et. al,2010, Ball, and (ولذلك فإن إعداد المعلمين المؤهلين والمدربين تدريبا وافيا

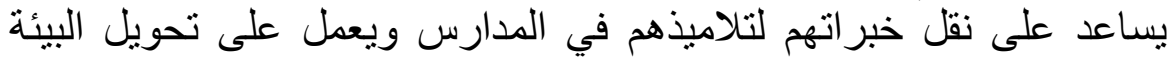

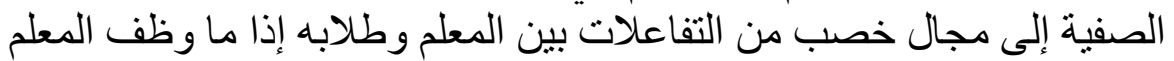

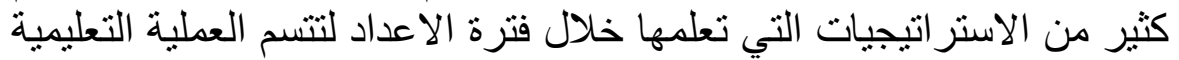

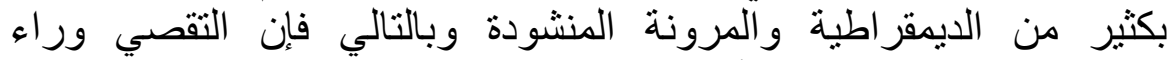

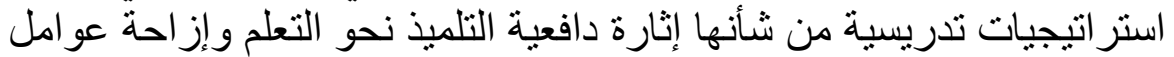

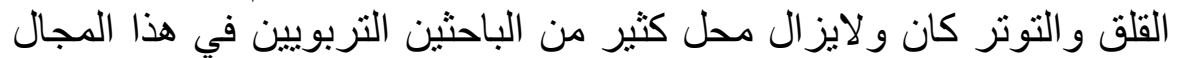

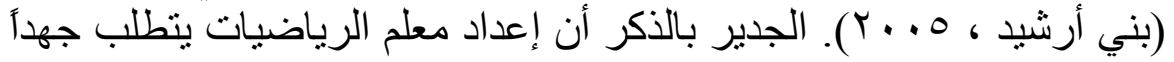

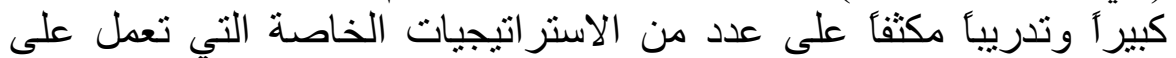

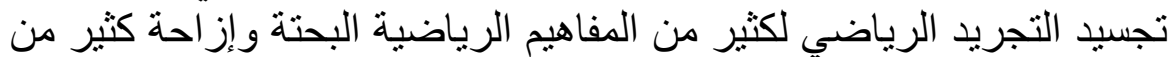

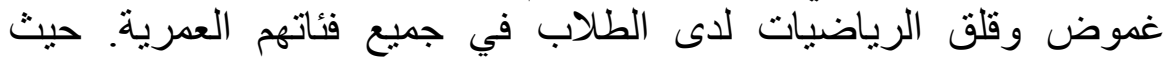

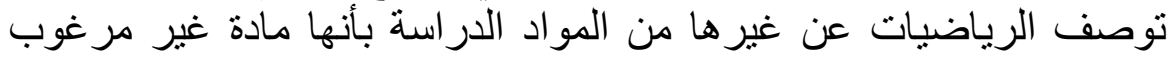

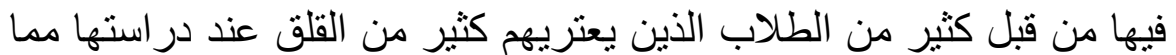

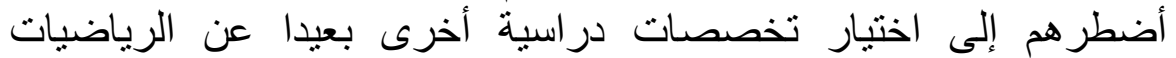

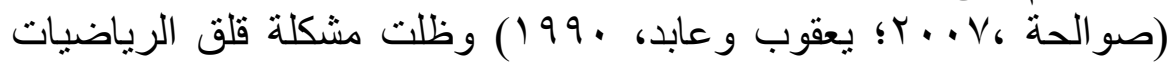

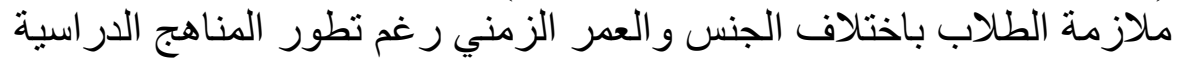

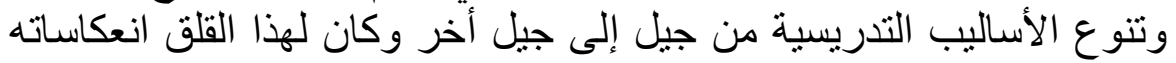

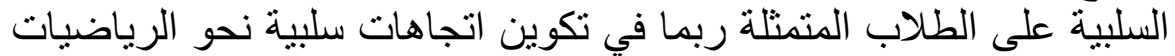

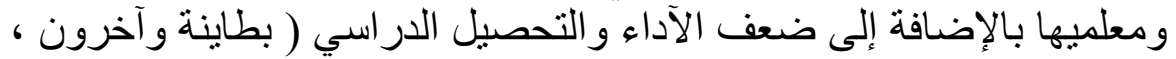

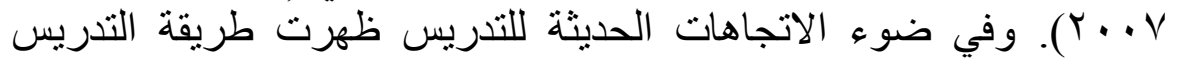

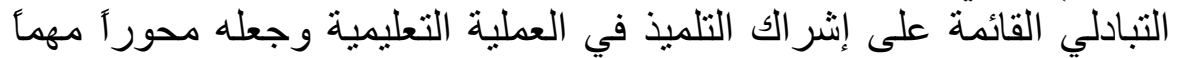

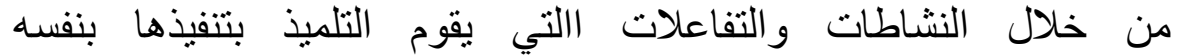
(Lori,2003) مما يعطيه كثير آ من الاستقلالية والاعتماد الذاتي لتنمية قدر اتهات 
الذاتية بشكل واسع وهي الاستر اتيجية ذاتها التي تناولها البحث الحالي بمزيد

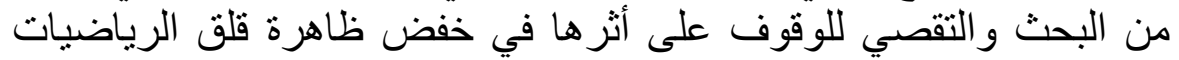

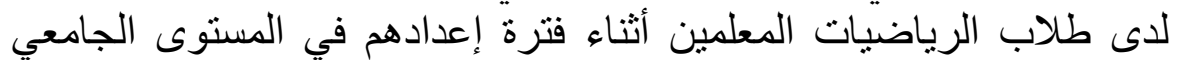

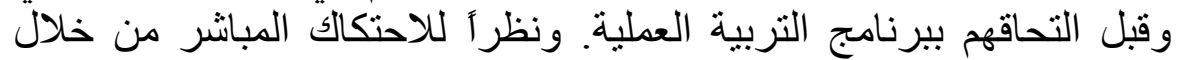

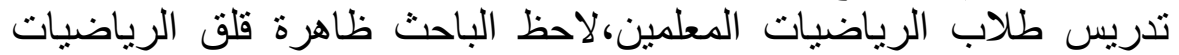

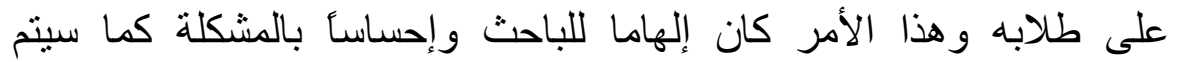
توضيحه في كيفية الشعور و الإحساس بمشكلة الدر استة.

\section{الشعور بالمشكلة:}

من خلال خبرة الباحث في التدريس الجامعي لطلاب الرياضيات المعلمين فقد

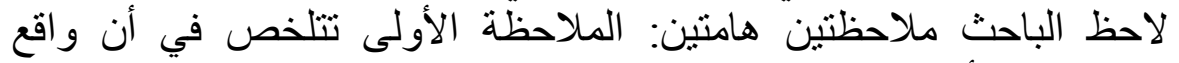
التدريس في أغلب الجامعات السعودية يعتمد على الطرق التقات التقليدية مثل طريقة

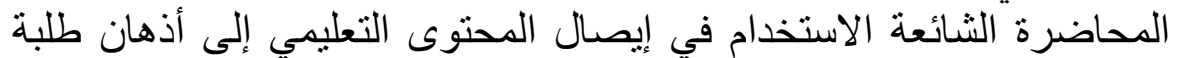

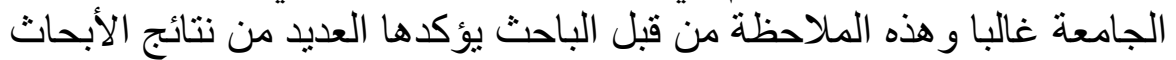

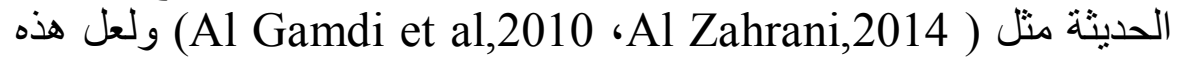

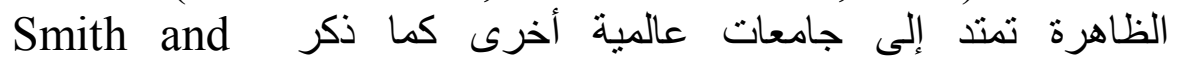

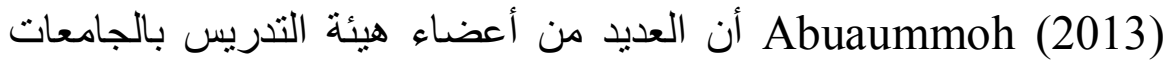

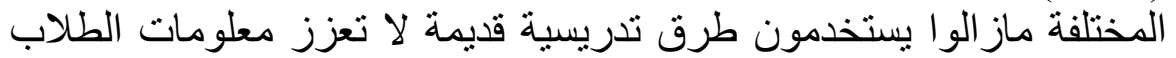

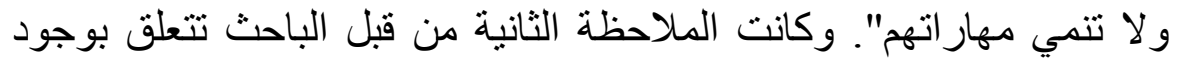

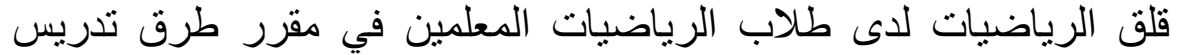

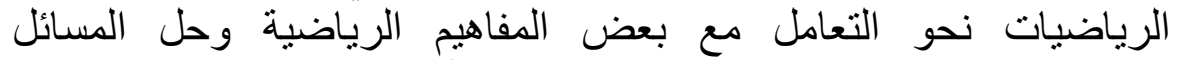

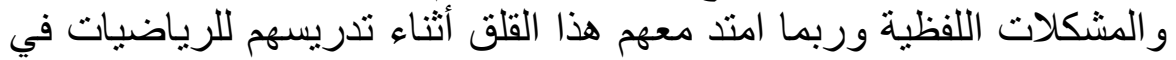

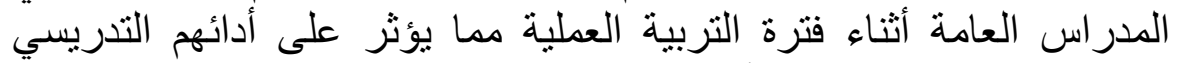

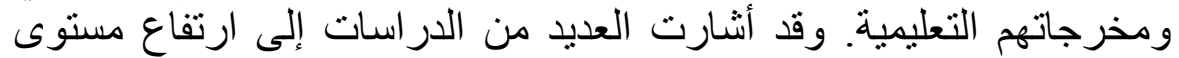
قلق الرياضيات بين أوساط طلبة الجامعة ومنها در اسة (Caroll, 2003)

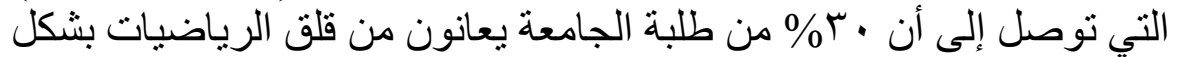

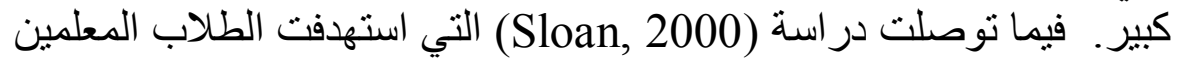

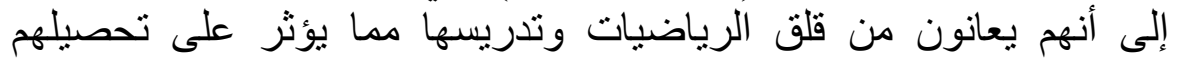

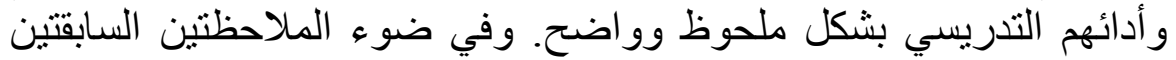

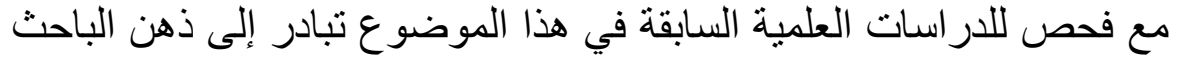

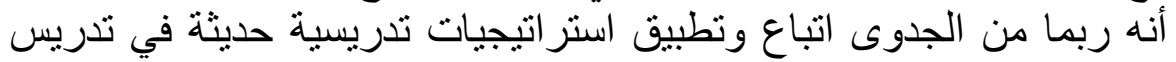




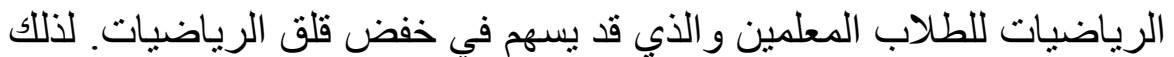

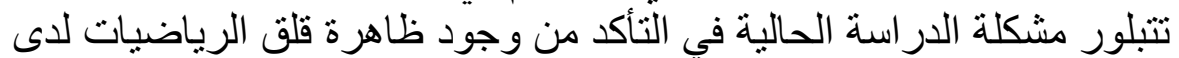

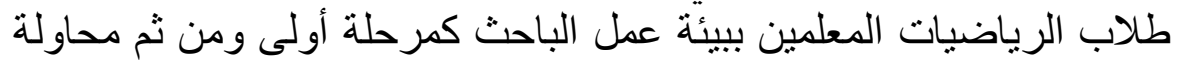
إيجاد علاج يعمل على تخفيض هذا القلق من خلالالدر اسة الحالية القائمة على التى

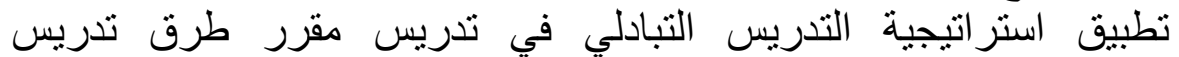

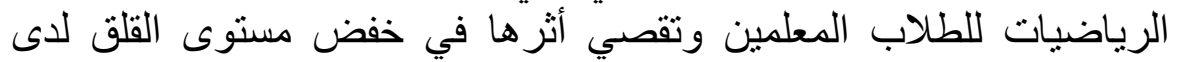

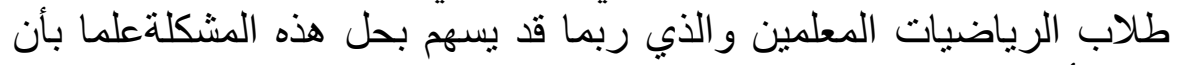

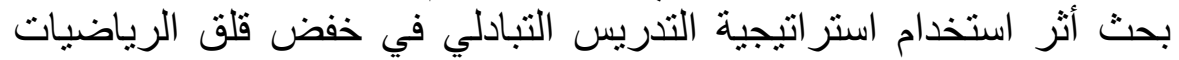

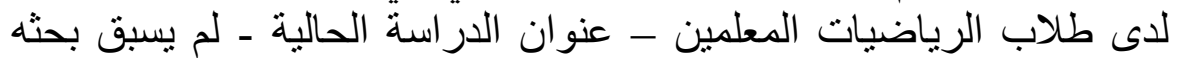
وتقصي نتائجه من قبل الباحثين في دراسات أخرى على على حد علم الباحث.

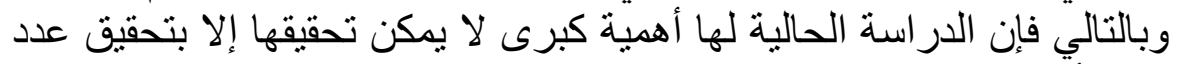

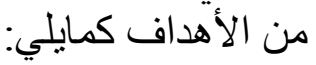

أهمية اللدر اسة: مداهية

ترجع أهمية الدر اسة الحالية لدر اسة أثز استخدام استر اتيجية التدريس التبادلي على قلق الرياضيات لاى ألى عينة من طلاب الرئة الرياضيات المعلمين بالكلية

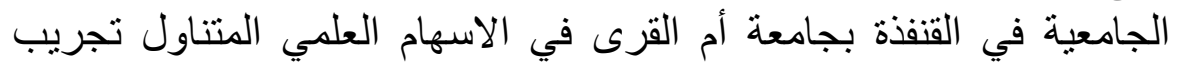

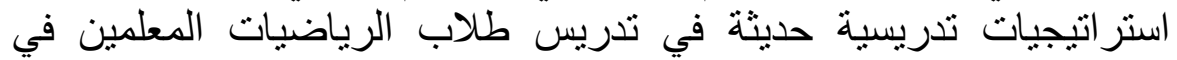

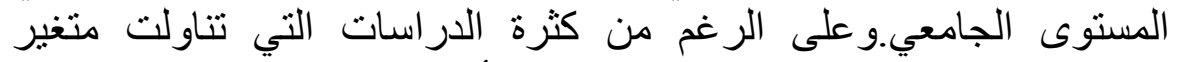

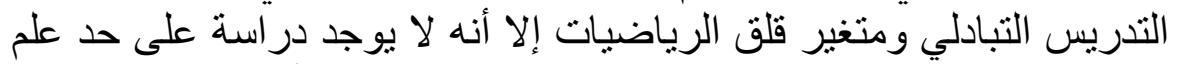

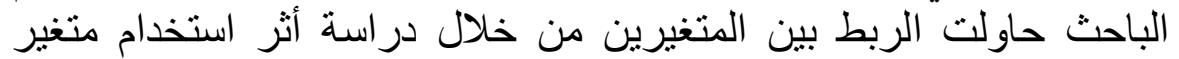

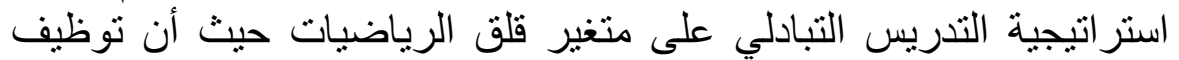

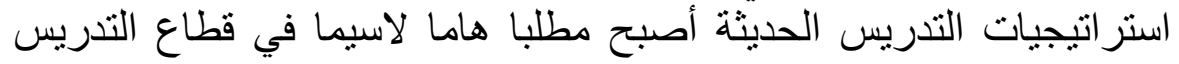
الجامعي.

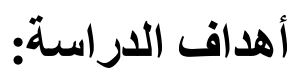

1 ـ تحديد مستوى قلق الرياضيات لدى طلاب الرياضيات المعلمين

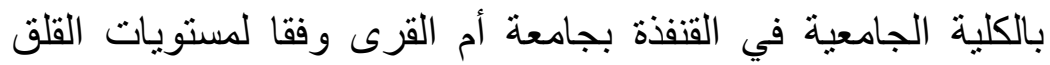

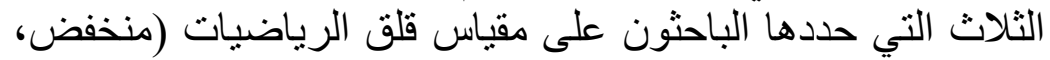
متوسط، مرتفع). 


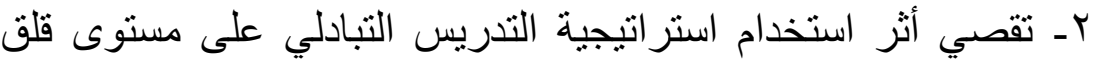

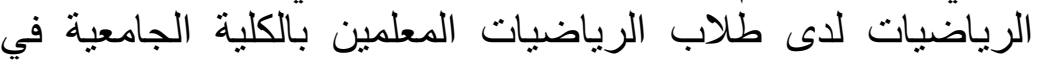

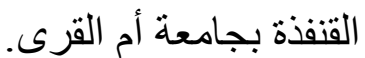

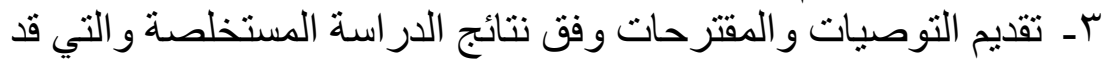

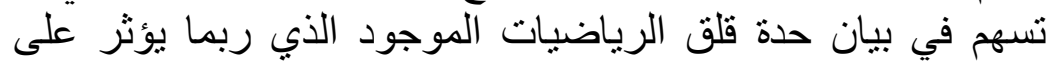

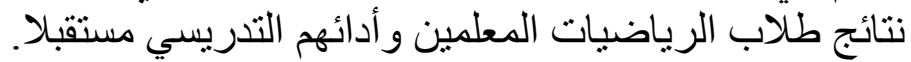

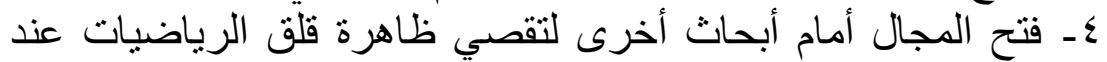
الطلاب المعلمين تحديدا و الوقوف على أسبات أسبها وكيفية علاجها.

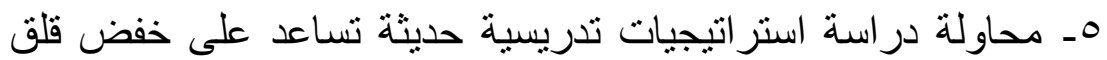
الرياضيات لدى طلاب الرياضيات المعلمين. أسئلة الدر اسةة:

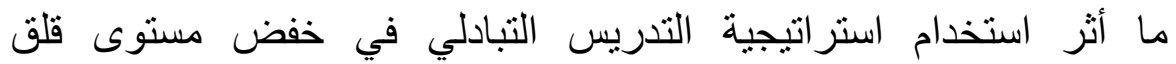

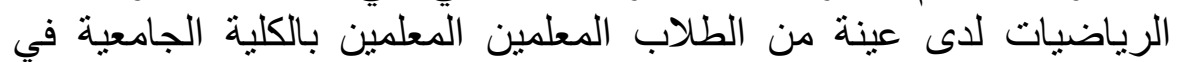
القنفذة بجامعة أم القرى في المملكة العربية السعودية؟ ويتفرع من هذا السؤال الرئيس التساؤلات الفرعية التالية: ا ـ ما مستوى قلق الرياضيات لدى طلاب الرياضيات المعلمين بالكلية

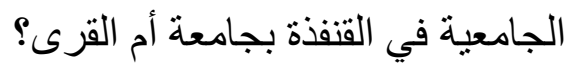

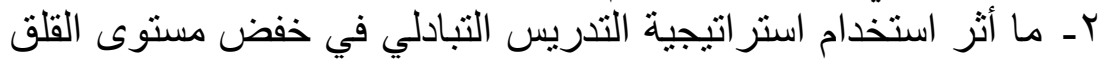

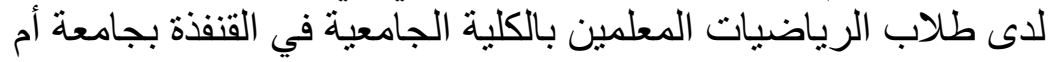
القرى؟

\section{فرضيات الدر اسة:}

هدفت الدراسة الحالية إلى التحقق من صحة الفرض التالي: توجد فروق ذات دلالة إحصائية متوسط درجات طلاب الرياضيات المعلمين

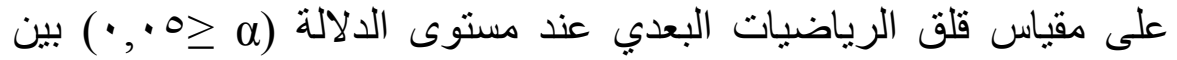

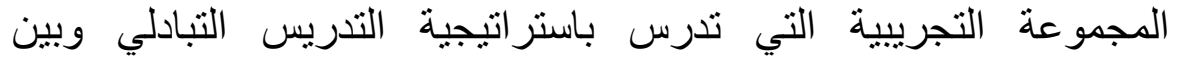
المجمو عة الضابطة التي تدرس بالطريقة التقليدية (المحاضرة). 

اقتصرت الدر اسة الحالية على:

ا - عينة من طلاب الرياضيات المعلمين بالكلية الجامعية في القفذة

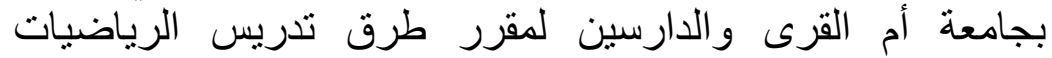

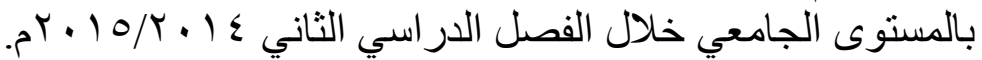

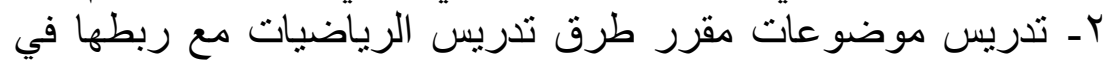

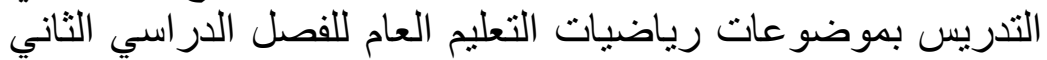

$$
\text { . } r \cdot 10 / r \cdot 1 \leq
$$

\section{منهج وأدوات الدراسة:}

اعتمدت الدر اسة الحالية على توظيف المنهج شبه التجريبي واستخدام مقياس The mathematics anxiety Rating (MARS) قلق الرياضيات الشهير

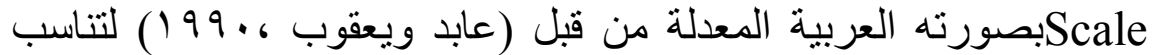

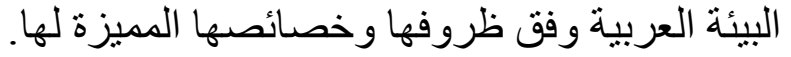

$$
\text { مصطلحاث الدراسة: }
$$

استراتيجية التدريس التبادلي:(Reciprocal Teaching Strategy):هي

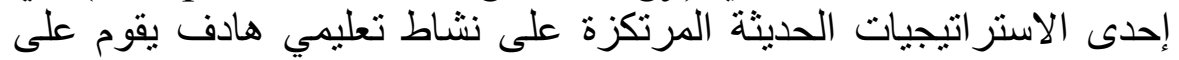

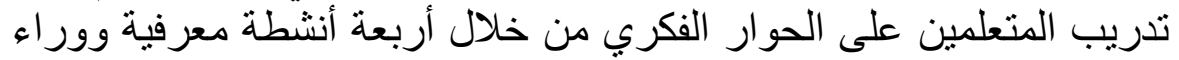

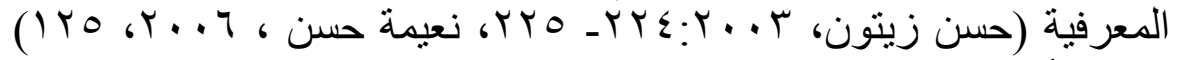
و هذه الأنشطة يمكن سردها بايجاز كما يلئي:

( أ) أتلخيص (Summarizing)

وفي هذا النشاط يقوم الطلاب بتلخيص الموضوع أو المادة المتناولة في فقرة

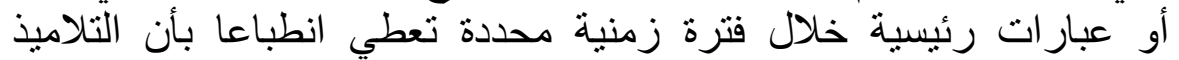
استتنجوا الملخص المفيد في أقل تعبير واضح زئح ودقيق (دونالد، وآخرون (2003

(ب) (ب) التوضيح (Clearfing) و فيه يتم توجيه الطلاب إلى توضيح ما قد يرد في الدرس من عبار ات ومفاهيم تحتاج مزيدا من التوضيح و إعطاء إشار ات توضيحية للوصول فئ إلى في فهمها وقد 
يحدث من خلال استيضاح الطلاب من بعضهم البعض أيضا ليزيد من زيادة التفكير ومحاولة القدرة على التفسير و الفهم.

( ج) التبؤ أو التوقع ( Prediction)

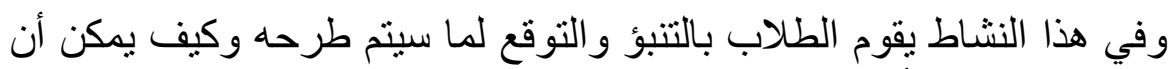

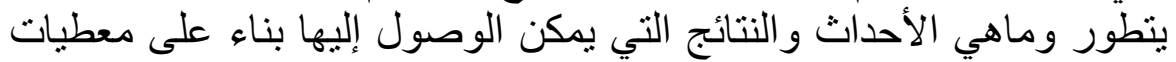

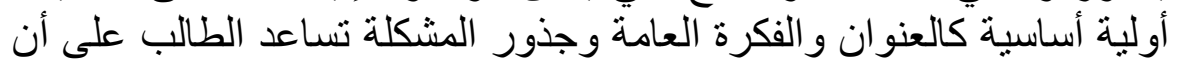
يتوقع توقعا منطقيا مبنيا على أسس ومقدمات العات أولئية

\section{(د) توليا الأسئلة (Questions generating)}

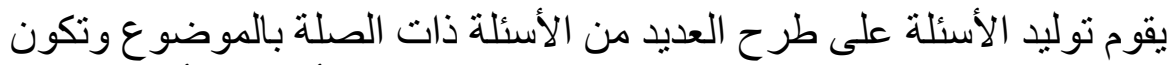

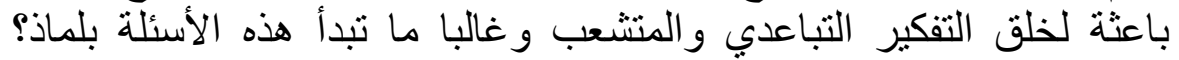

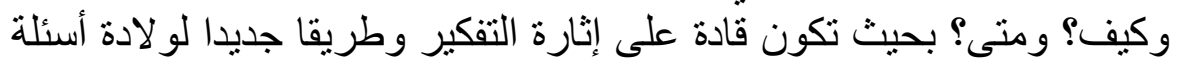

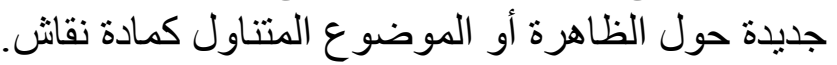

مستوى قلق الرياضيات:هو المستوى الذي يعبر عنه بالدرجة التي يحصل

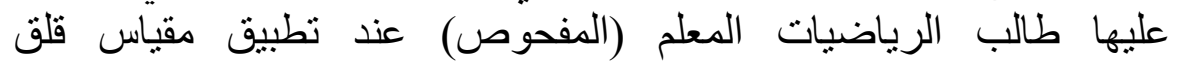
الرياضيات (MARS) المصدم والمستخدم في هذه الدر اسة.

طلاب الرياضيات المعلمين: هم طلاب طرق تدريس الرياضيات الذين

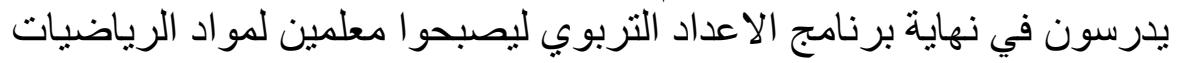
في مر احل التعليم العام في إحدى المدارس الحعاد الحكومية مستقبلا.

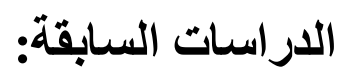

يمزج موضوع الدراسة الحالية بين متغيري استراتيجية التدريس التبادلي

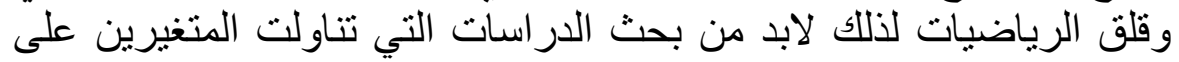
حده من قبل الباحثين كما يلي: (أ) دراسات تناولت قلث الرياضيات لاى الطلاب: بحثت العديد من الدر اسات قلق الرياضيات لدى الطلاب في المدر اس ووجدت

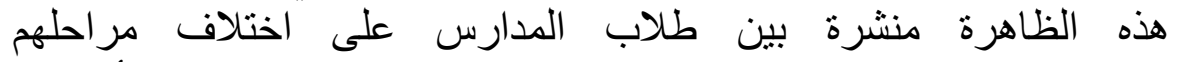

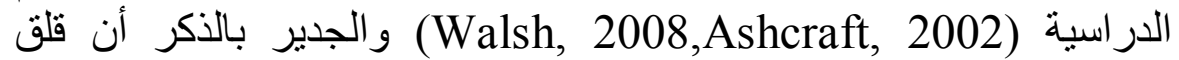
الرياضيات ليس محصور ا على طلبة المدر اس فقط أو فئة دون فئة أخرى بل بل 


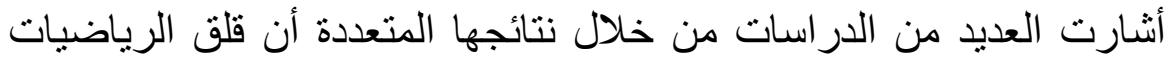

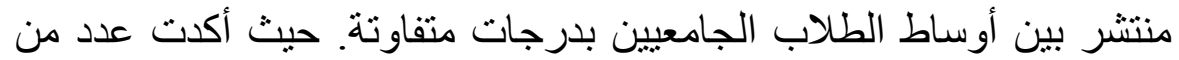

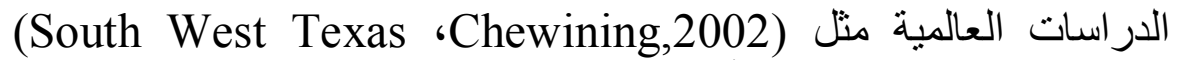

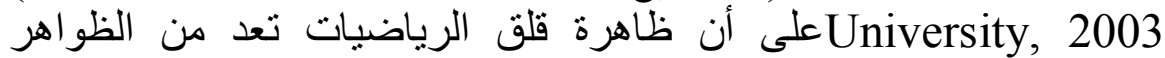
المنتشرة بين طلاب الجامعات لأسباب متعددة وهو الأمر ذاته الذات الذي أكدته

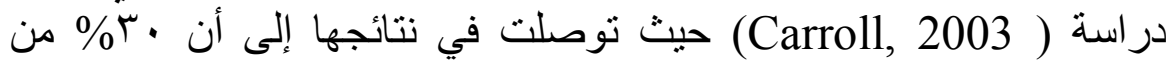
طلاب الجامعة لديهم مخاوف وقلق من الرياضيات. فيما خص التص (

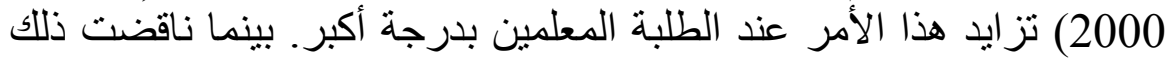

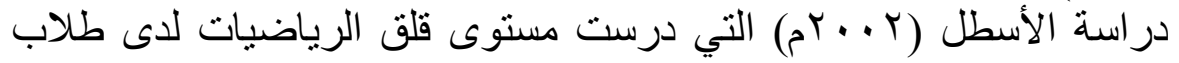

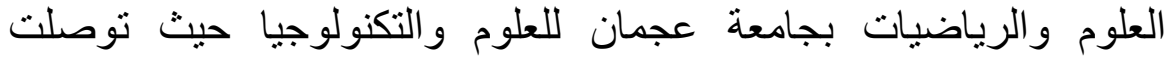

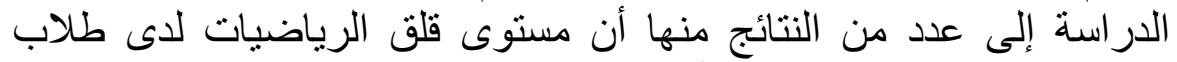

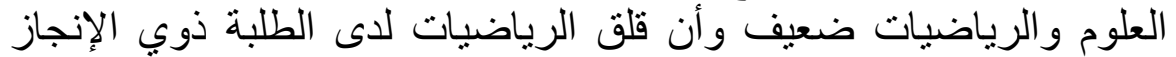

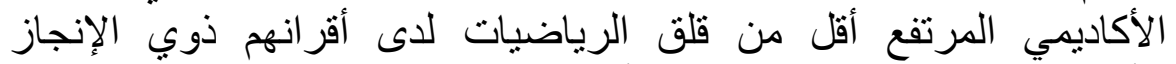

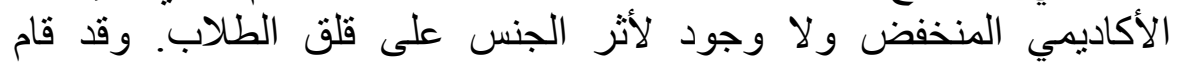

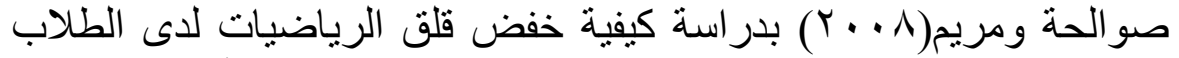

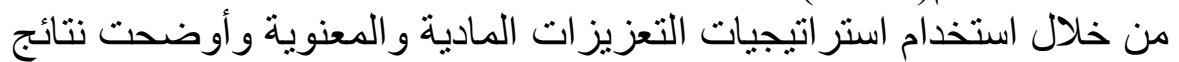

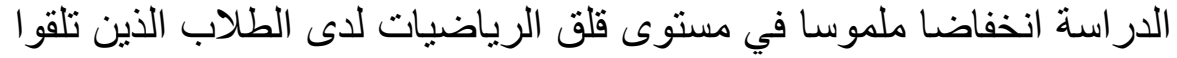

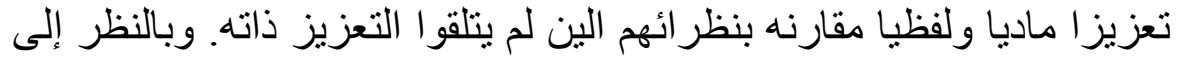

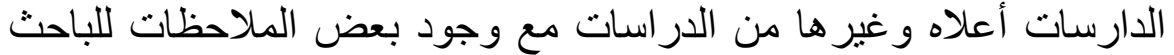

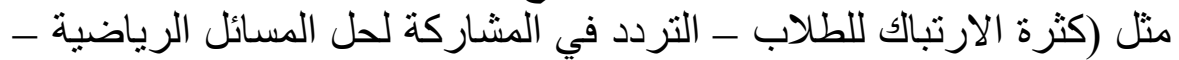

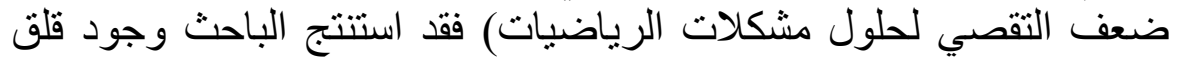

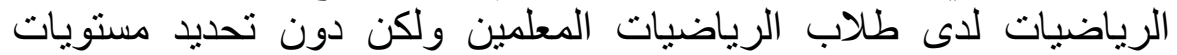

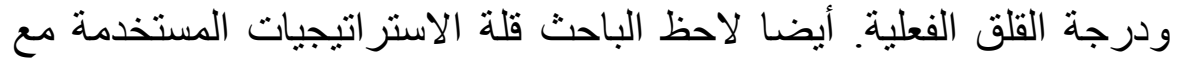

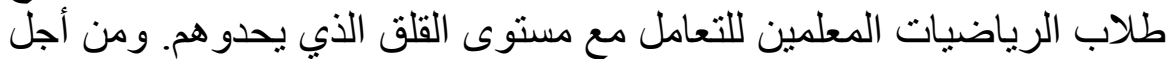

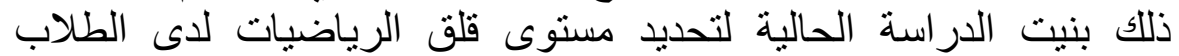

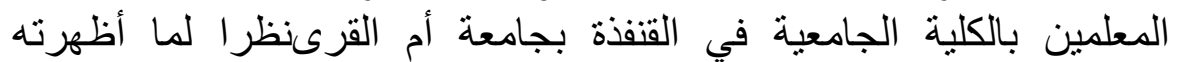

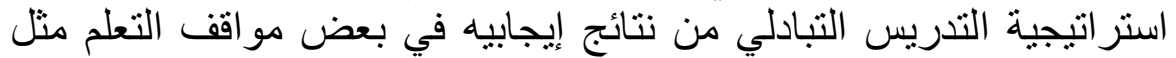

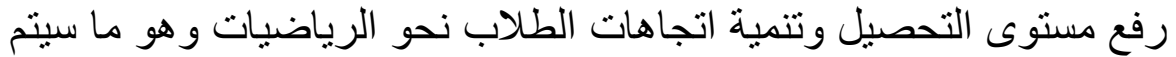

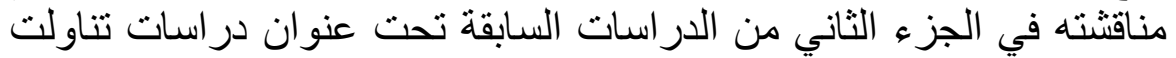
استر اتيجية التدريس التبادلي. 


\section{(ب) دراسات تناولت استراتيجية التدريس التبادلي:}

أثبتت العديد من الدراسات التي استخدمت استراتيجية التدريس التبادلي

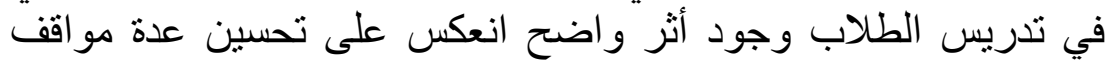

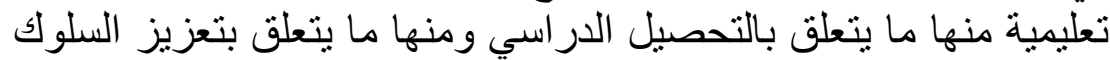

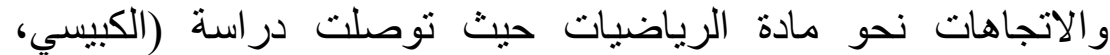

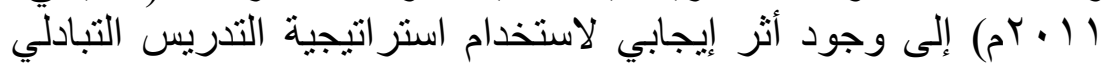

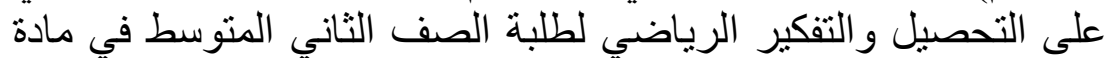
الرياضيات من خلال تفوق نتائج المجموعة التجريبية مقارنة بنتائجة

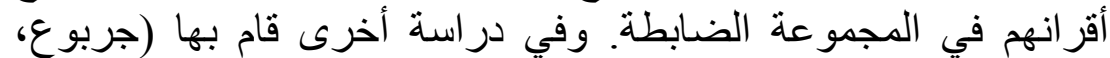

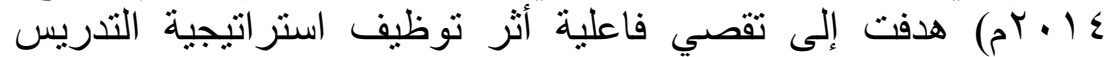

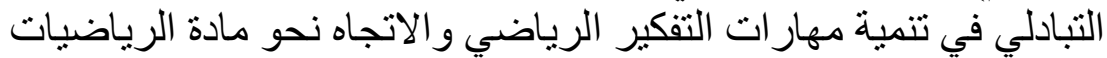

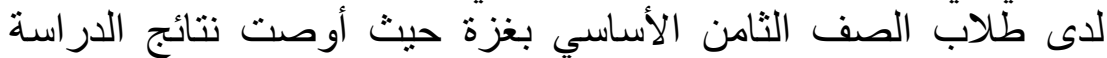

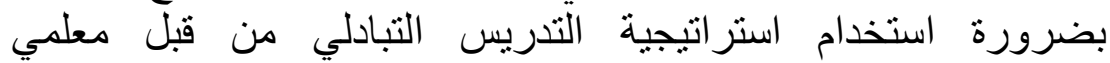

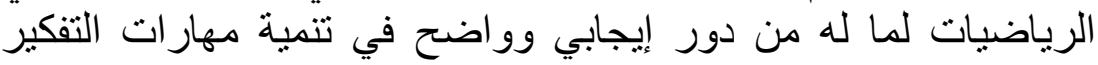
الرياضي والاتجاهات الإيجابية نحو مادة الرياضيات دوريات. كما بحث (عفانة

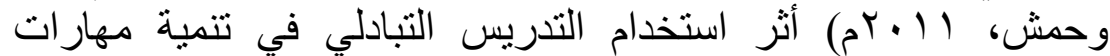

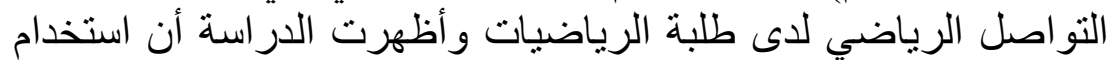

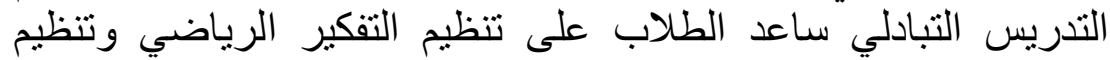
المو اقف و العلاقات الرياضية بصور مختلفة وسهل على الطيادي الطلاب استخدام

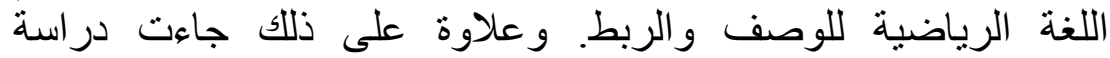
(Nadine Spore, 2009)

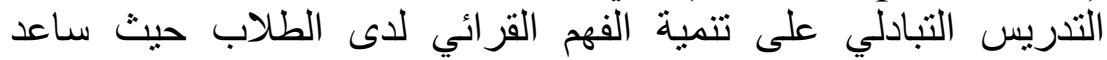

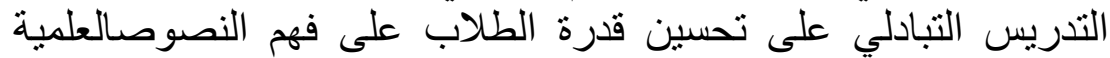

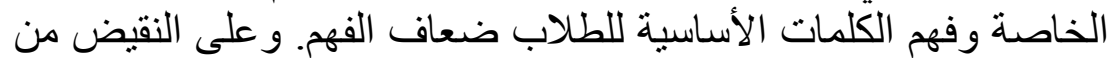

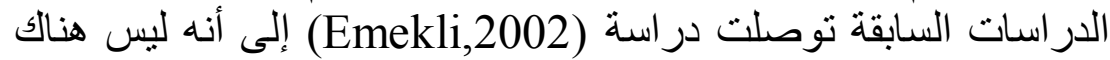

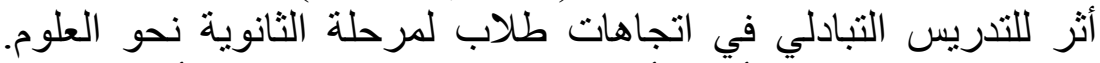

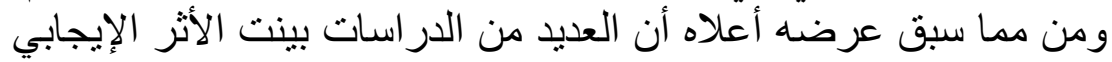

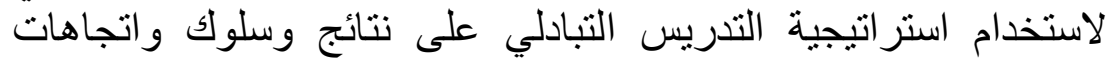

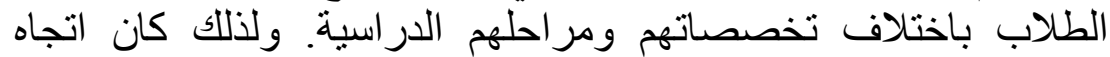




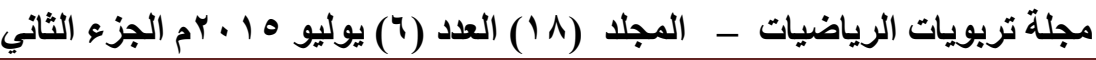

الباحث يميل إلى توظيف استر اتيجية التدريس التبادلي في موضوع هذانه

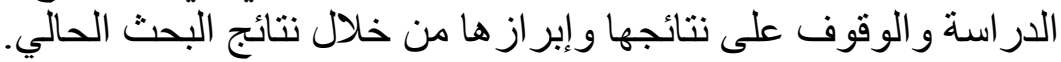

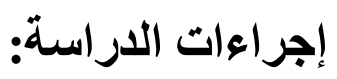

أولا/ إجراءات تحديد مستوى قلق الرياضيات القبلي (قبل تطبيق الاستر اتيجية).

\section{مجتمع وعينة الار اسة:}

تكون مجتمع الدراسة من جميع الطلاب الدراسين لمقرر طرق تدريس

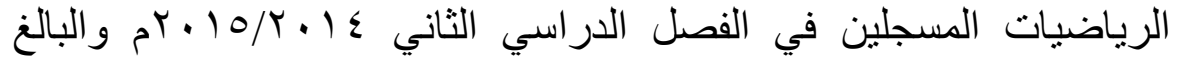

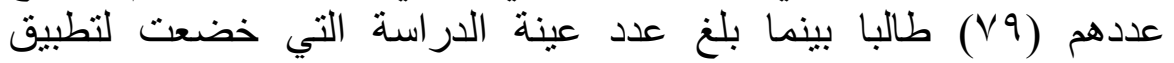
استر اتيجية التدريس التبادلي ( • (7) طالبافقط وهم الذين يعانون من درجة قلق

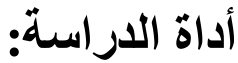

قام الباحث باستخدام اختبار قلق الرياضيات الثهير (MARS) عن طريق

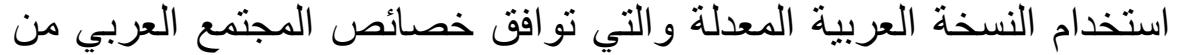

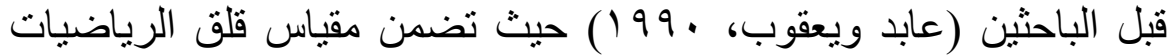

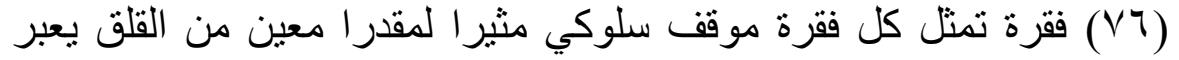

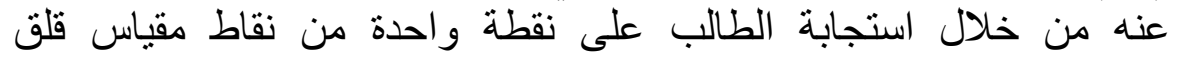

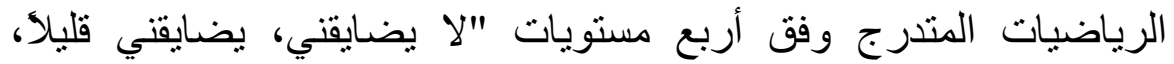

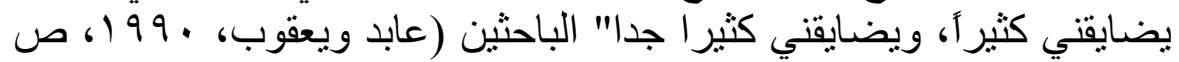

بعد إعداد مقياس قلق الرياضيات في صورته الأولية قام الباحث بإعادة تقنينه

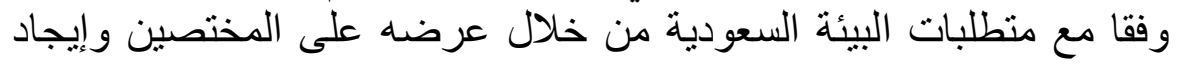
درجات الصدق والثبات حتى يكون المقياس في صورته النهائية وفق الخطو ات التالية:

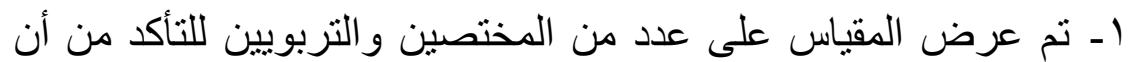

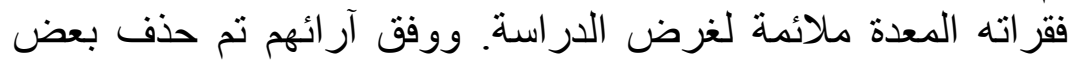

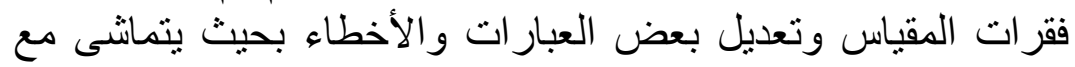


خصائص البيئة السعودية ليصبح عدد فقرات مقياس قلق الرياضيات

$$
\text { (60) فقرة في صورتها النهائية. }
$$

r- تم تطبيق المقياس على المجموعة التجريبية و المكونة من (· (ب) طالبا

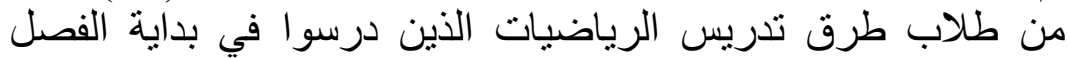

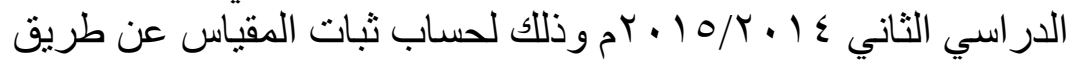

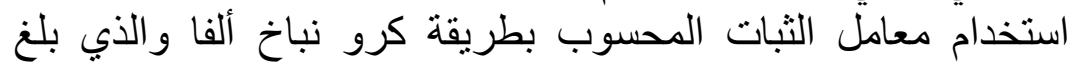

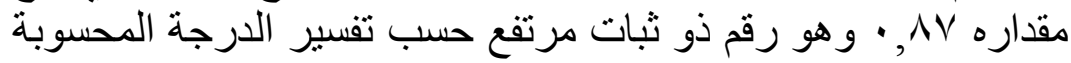
على مقياس كرونباخ.

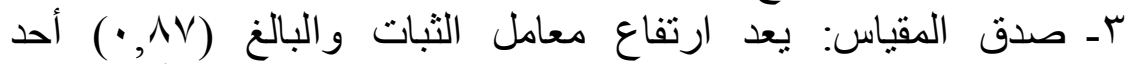

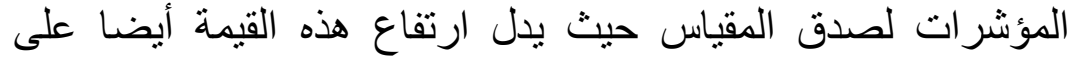

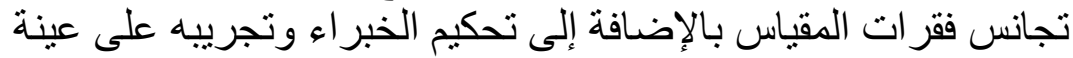

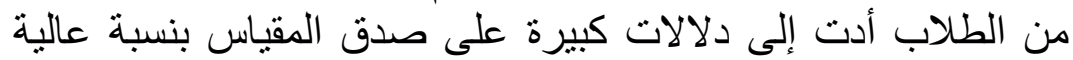
بحيث يقيس ما أعد من أجله.

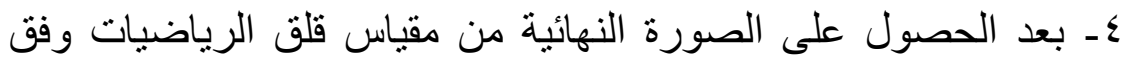

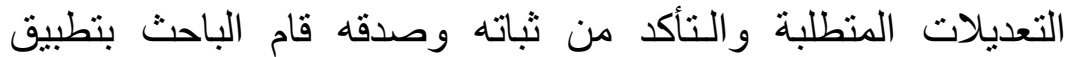

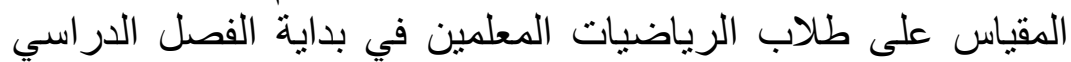

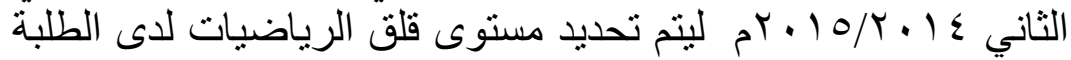

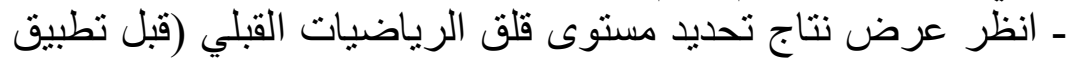

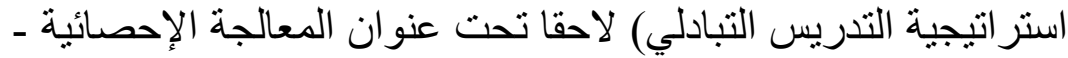

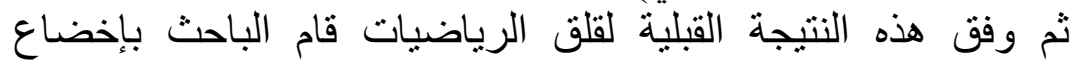
الطلاب ذوي القلق المرتفع فقط لاستر اتيجية التدريس التبادلي لتقيصي

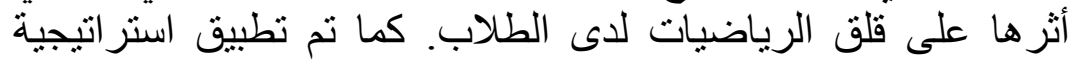

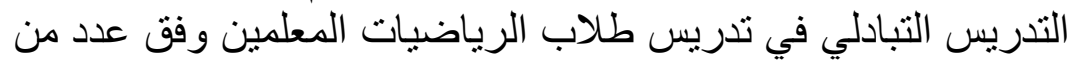

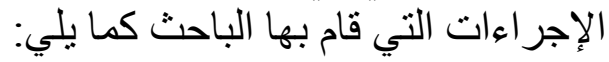

$$
\text { ثاتيا/ إجراعات استخدام التدريس التبادلي. }
$$

(أ) اختيار المحتوى التعليمي لطلاب الرياضيات المعلمين:

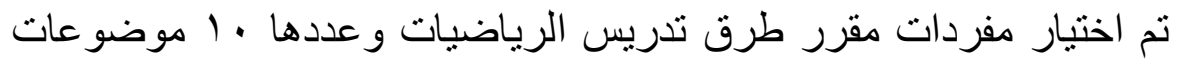
ليتم تدريسها وفق استراتيجية التدريس التبادلي على تلى مدار الفصل التصليس الدراسي 


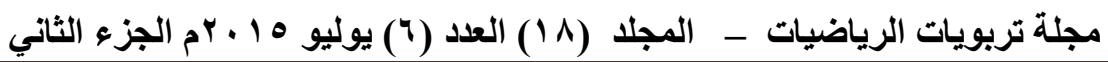

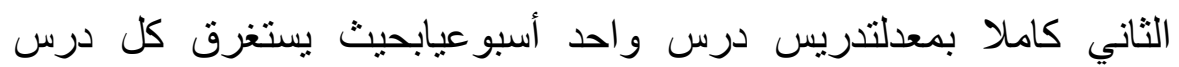

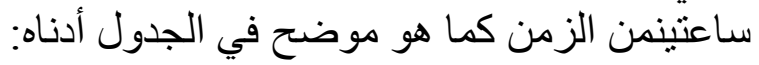

جدول (1) محتويات التعلم لمقرر طرق تدريس الرياضيات

\begin{tabular}{|c|c|c|c|}
\hline ساعات التدريس & عدد الأسـابيع & قائمة الموضوعات & م \\
\hline$r$ & 1 & طرق حل مشكلات الرياضيات & 1 \\
\hline r & 1 & أساليب حل المعادلات الرياضية & r \\
\hline$r$ & 1 & مهارة طرح الأسئلة الرياضية & $r$ \\
\hline r & 1 & طرق التفكير في الرياضيات & $\varepsilon$ \\
\hline$r$ & $T$ & تدريس المفاهيم والمهارات الرياضية & 0 \\
\hline$r$ & 1 & أساليب البرهان الرياضي & 7 \\
\hline r & 1 & تحليل المحتوى التعليمي للرياضيات & $\mathrm{V}$ \\
\hline$r$ & 1 & الاستقراء والاستنباط الرياضي & $\Lambda$ \\
\hline r & 1 & استخدام النماذج و المحسوسات & 9 \\
\hline r & 1 & الطريقة المعملية لتعلم الرياضيات & 1. \\
\hline
\end{tabular}

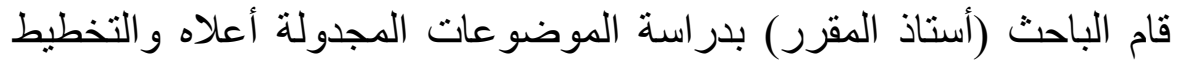

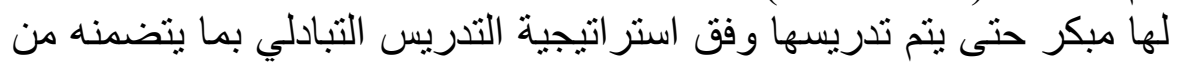

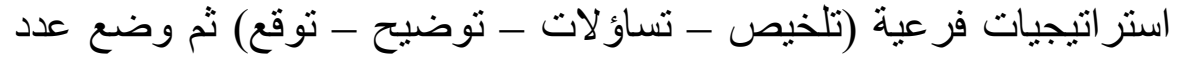
من الخطوات لتنفيذ استر اتيجية التدريس التبادلي كما يلي: لتئي (ب) خطوات استراتيجية التدريس التبادلي: قام الباحث (أستاذ المقرر) بعدة خطوات لتنفيذ استر اتيجية التدريس التبادلي كما يلي: قام الياحي:

ا ـ قاد الباحث الحوار في البداية وطبق استر اتيجيات التدريس التبادلي مثاني

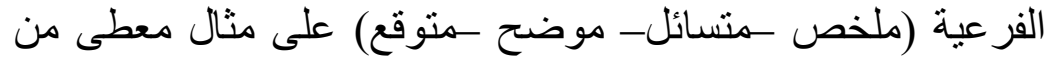

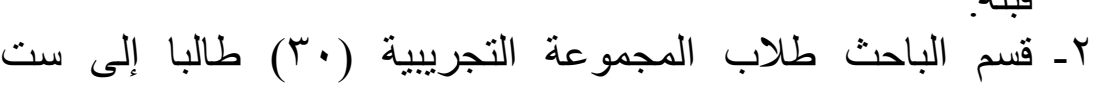

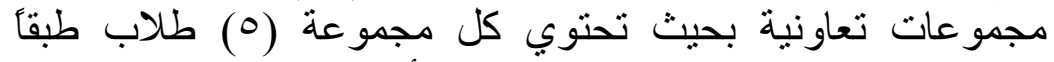

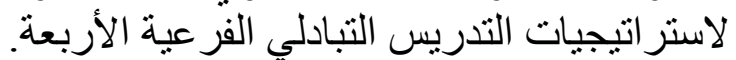

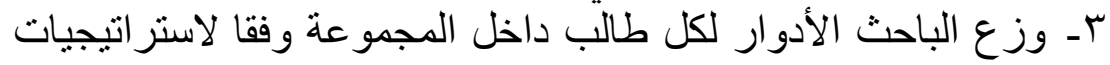

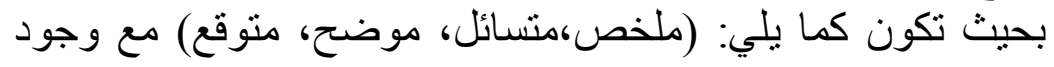


قائد لكل مجموعة ولاحقا يتم تبادل أدوار الطالب القائد مع زملاؤه داخل المجمو عة قدر الامكان. ع - يبدأ الحوار التبادلي داخل كل مجمو عة مع قيادة المعلم له و إعطاء إلهاء

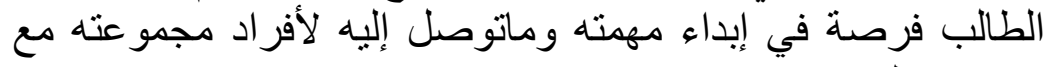
اجابتهم على استفسار اتهم. هـ تدريب الطلاب على مثل الأنشطة السالفة الذكر وتكرارها حتى الذه

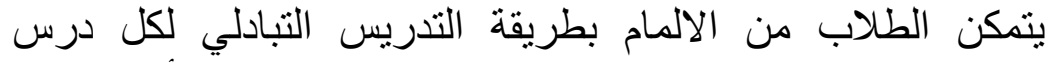

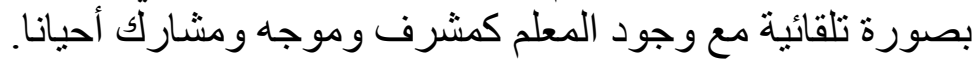
وفي المقابل تم تدريس طلاب المجموعة الضابطة(·r) طالبا بالطريقة التقليدية (المحاضرة) لنفس المحتوى التعليمي ونفس المدة الزمنية. ثالثًأ: إجراعات تحديد مستوى قلق الرياضيات البعدي (بعد تطبيق الاستر اتيجية).

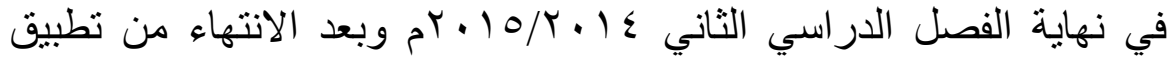

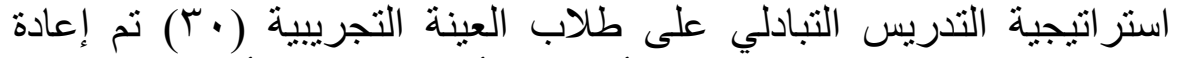

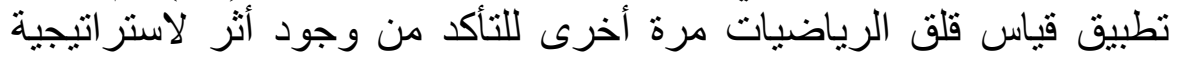

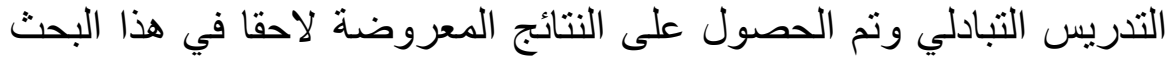
تحت عنوان المعالجة الإحصائية. رابعاً: المعالجة الإحصائية: نتائج تحديد مستوى قُق الرياضيات القبلي (قبل تطبيق الاستر اتيجية).

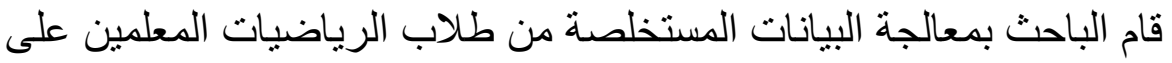

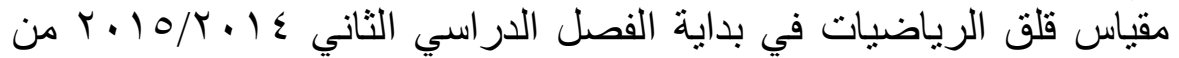

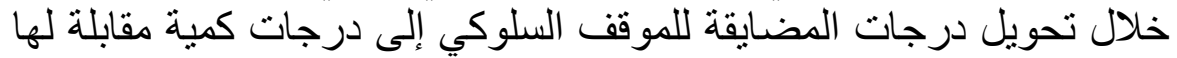

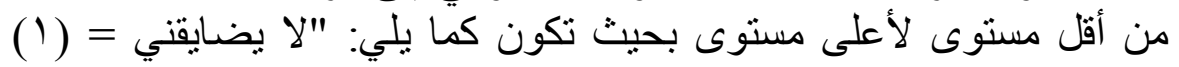

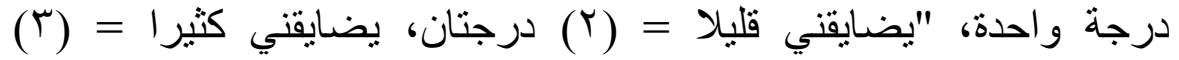

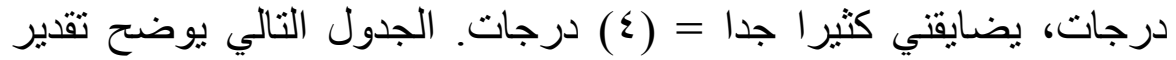
درجة المضايقة ووزنها الكمي كما يلي: لئيا 


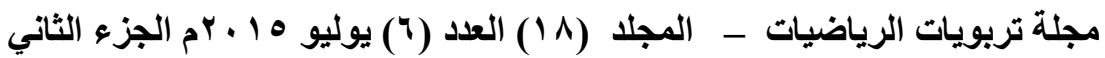

جدول (r) ) درجة المضايقة للموقف السلوكي ووزنها الكمي

\begin{tabular}{|c|c|c|}
\hline الوزن الكمي & درجات المضايقة للموقف السلوكي & r \\
\hline 1 & لا يضايقني & 1 \\
\hline r & يضايقتى قليلا & $r$ \\
\hline$r$ & يضايقتي كثيرا & $r$ \\
\hline$\varepsilon$ & يضايقني كثيرا جدا & $\varepsilon$ \\
\hline
\end{tabular}

وحيث أن عدد فقرات مقياس قلق الرياضيات التي تم تطبيقه على الطلاب

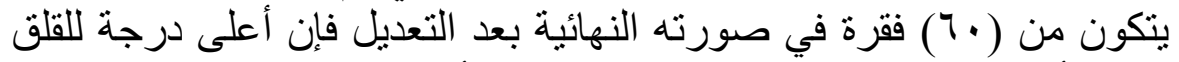

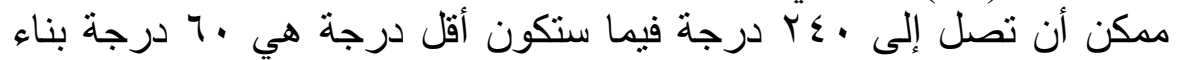

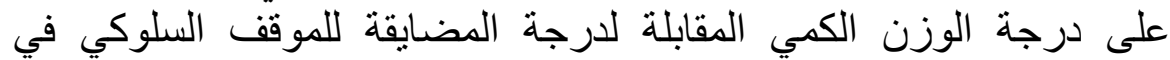
الجدول رقم (r) - (ب).

ونظر التساوي المسافات التي تفصل بين الدرجات الأربع المقدره كميا فقد

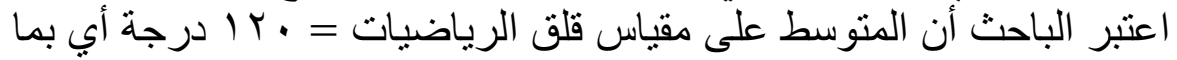

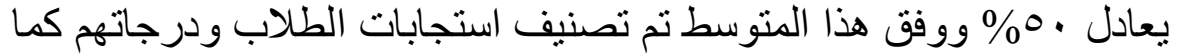
يلي:

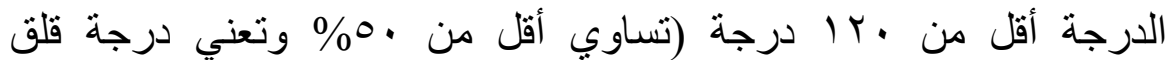
منخفض)

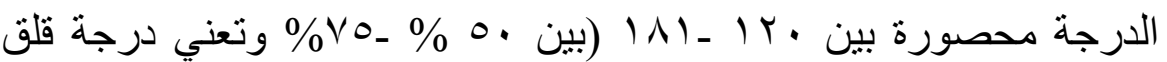
متوسط) الدرجة أكبر من /1 | درجة (أكبر من \0\% وتعني درجة قلق مرتفع)

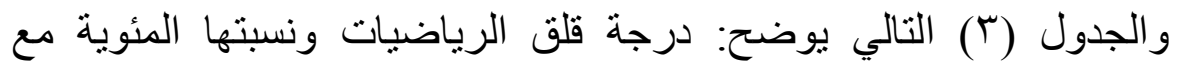

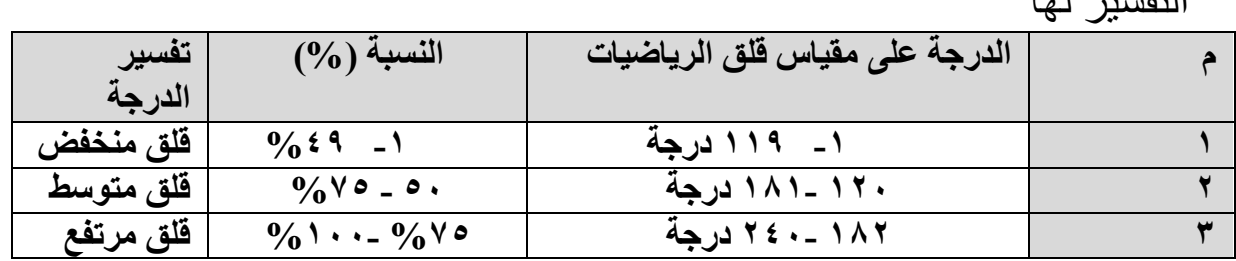

عرض التتائج وتفسيرها: للإجابة عن السؤال الأول في هذه الدراسة و الذي ينص على ما يلي: 
ا ـ ما مستوى قلق الرياضيات لدى طلاب الرياضيات المعلمين بالكلية

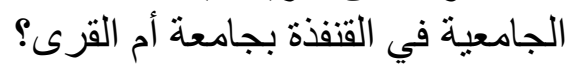

تم إخضاع مجتمع الدر اسة الكلي (V9) طالبا لمقياس قلق الرياضيات في بداية

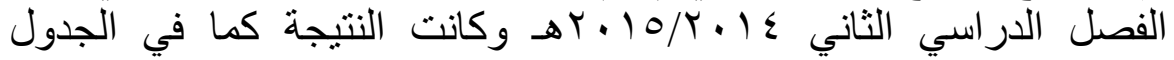
التالي:

جدول (؛ ) المتوسط الحسابي والانحر اف المعياري والنسبة المئوية لارجات الطلاب

\begin{tabular}{|c|c|c|c|}
\hline $\begin{array}{c}\text { النسبة المئوية } \\
\text { (\%) }\end{array}$ & الانحراف & المتوسط الحسابي & عدد الطلاب \\
\hline$\% \vee 0, q \leq$ & $0, r Y$ & $|\wedge r, \leqslant|$ & $v q$ \\
\hline
\end{tabular}

من الجدول رقم (ع) نلاحظ أن المتوسط الحسابي لدرجات الطلاب على الحي

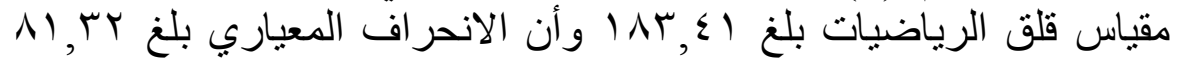

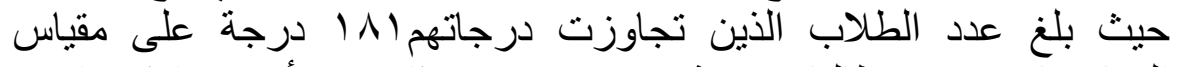

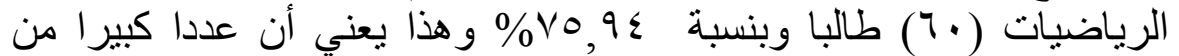

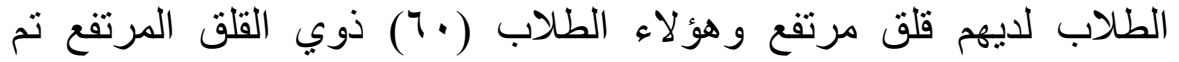

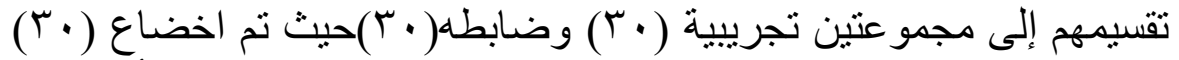

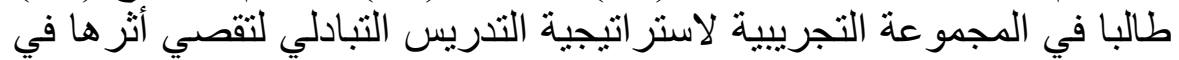
خفض قلق الرياضيات.

تتائج أثر استخدام استراتيجية التدريس التبادلي في خفض مستوى قلق الرياضنيات:

قام الباحث بإعادة تطبيق مقياس قلق الرياضيات مرة أخرى في نهاية الفصل التصل

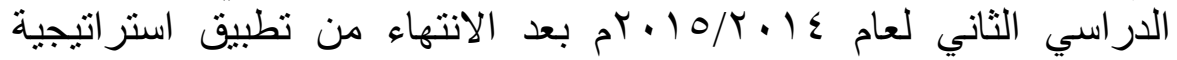

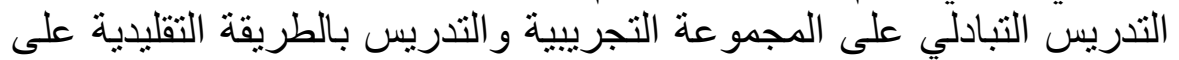

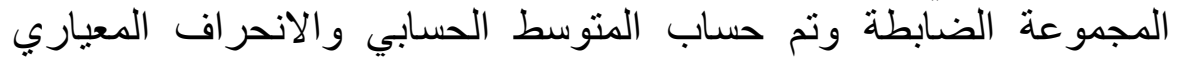

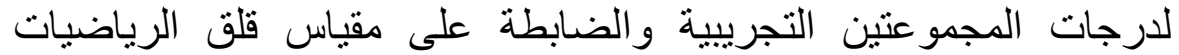

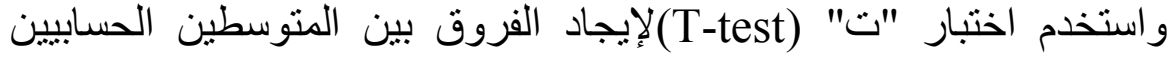
ودلالاتهما كما في الجدول التخدار التالي: 


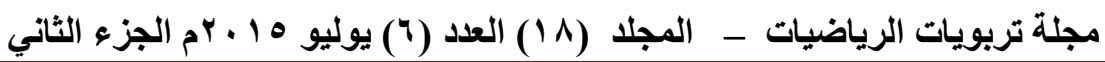

جدول (•): نتائج الاختبار "ت" لمقارنة المتوسطين الحسابيين للمجموعتين التجريبية

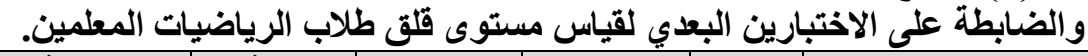

\begin{tabular}{|c|c|c|c|c|c|}
\hline الدلالة & "تيمة" & الالمعياري & الحستوسي & العينة & نتائج البيانات قلى مقيات الريات \\
\hline دالة إحصائيا & $* 1 \cdot, \wedge \varepsilon$ & 9,71 & $1 \leqslant r, \cdot v$ & r. & المجموعة التجريبية \\
\hline غير دائة & •,YYI & $0,+1$ & INY,YT & $r$. & المجموعة الضابطة \\
\hline
\end{tabular}

$(\cdot, \cdot \theta \geq \boldsymbol{\alpha}) *$

يتبين من نتائج الجدول رقم (0) أن قيمة "ت" لطلاب المجموعة التجريبية

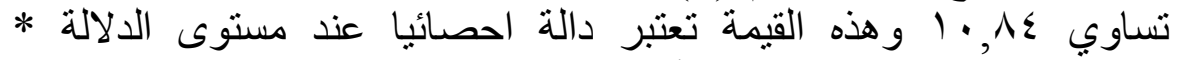

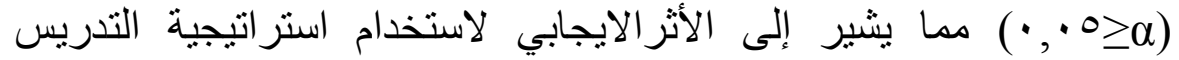
التبادلي في خفض قلق الرياضيات المرتفع لدى طلاب الرياضيات المعلمين الإين في المجمو عة التجريبية.

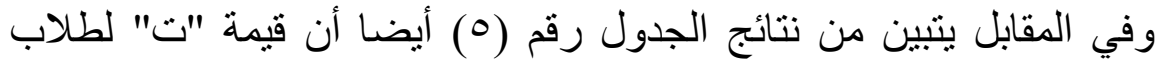

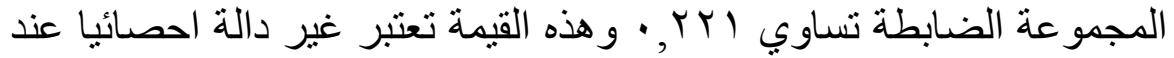

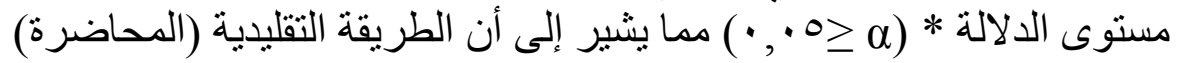

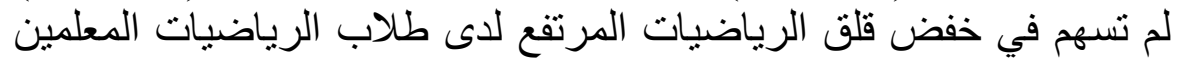
في المجمو عة الضنابطة.

وبالتي فإن إجابة السؤال الثاني للار اسة والذي ينص على ما يلي:

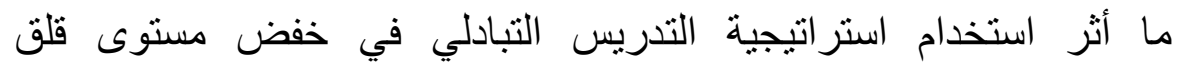
الرياضيات لدى عينة من الطلاب المعلمين بالكلية الجامعية في القنفذة بجامعة التئة

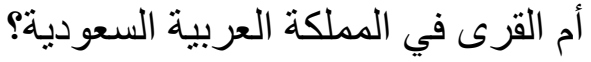

يمكن الإجابة عليهبأنه يوجد أثر إيجابي لاستخدام استر اتيجية التدريس التبادلي

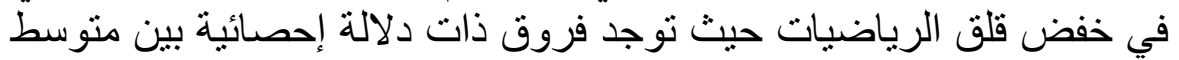

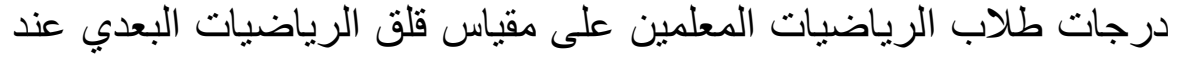

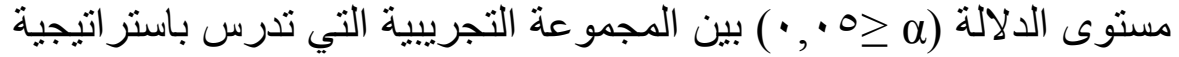
التدريس التبادلي وبين المجموعة الضابطة التي تدرس بلدئ بالطريقة التقليدية (المحاضرة)وتعزىهذه الفروق لاستخدام استر اتيجية التدريس التبادلي. 


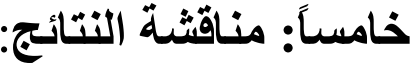

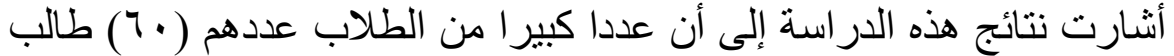

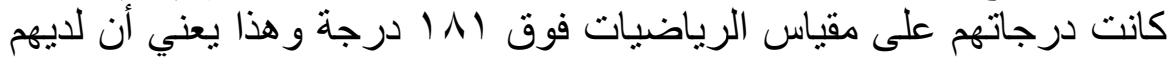

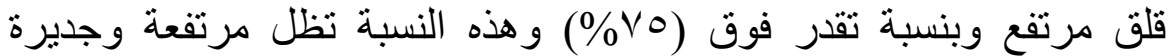

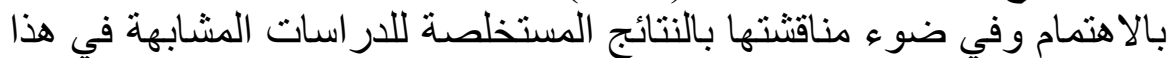
المجال نجد أن نتائج دراسة (South West TexasUniversity, 2003)

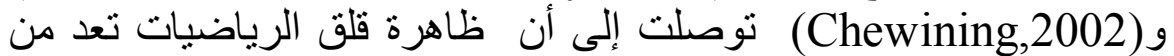
الظو اهر المنتشرة بين طلاب الجامعات بدرجات متفاوتة و أيدتها لاحقا در اسة إنة (Carroll, 2003)

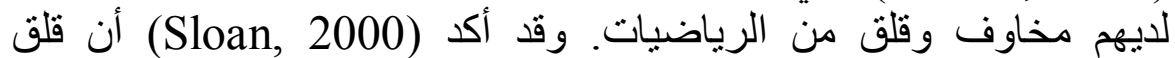

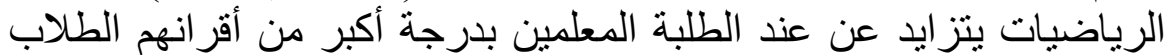

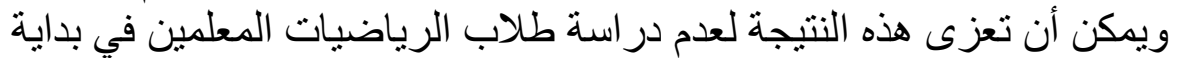

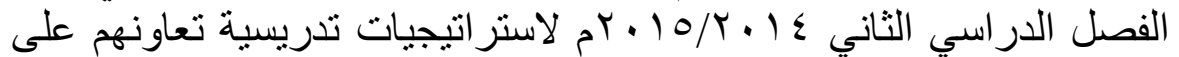

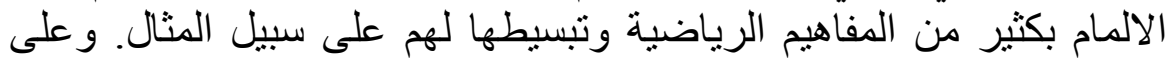

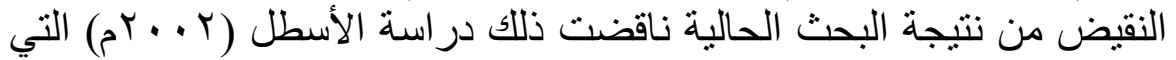
درست مستوى قلق الرياضيات لدى طلاب العلوم و الرياضيات بجامعة

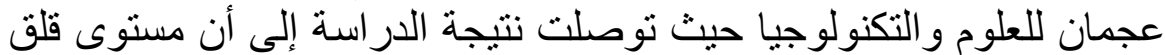

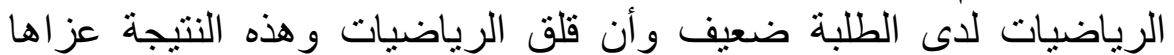

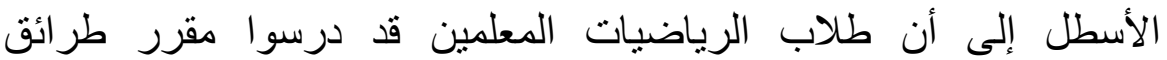
الرياضيات وتدربوا على كثير من الاستر اتيجيات المتعلقة بتدريس المفاهين فئين

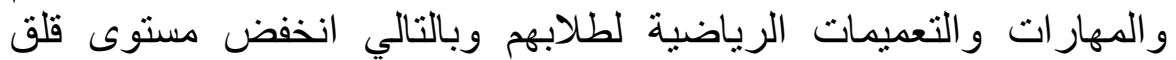

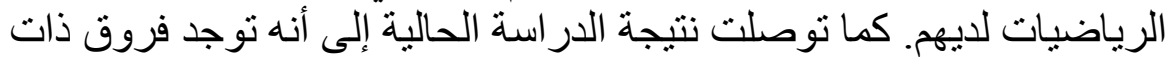
دلالة إحصائية بين المتوسطين الحسابيين للمجمو عتين التجريبية والضينة الضابطة

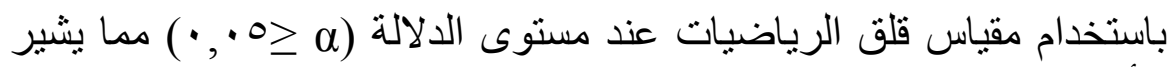

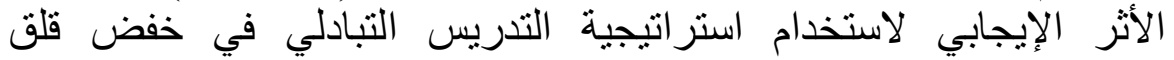
الرياضيات المرتفع لدى طلاب الرياضيات المعلمين في المجموعة التجينية التريبية.

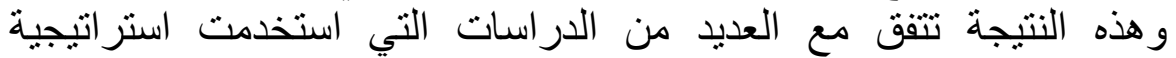

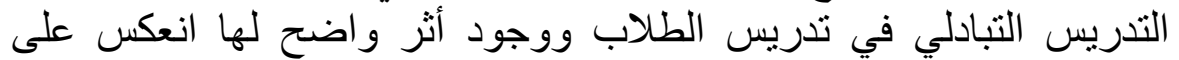

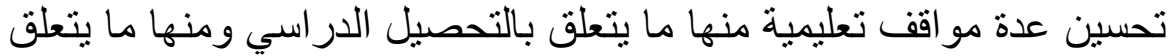

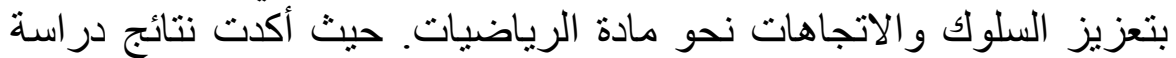




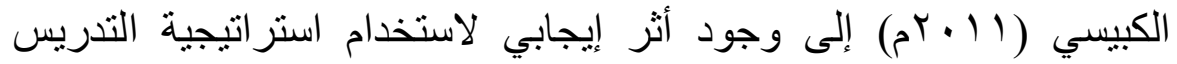

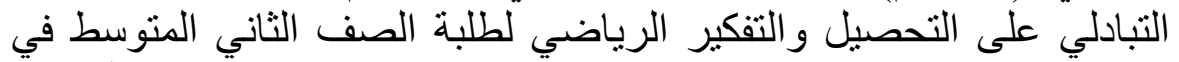

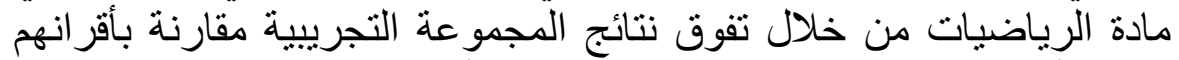

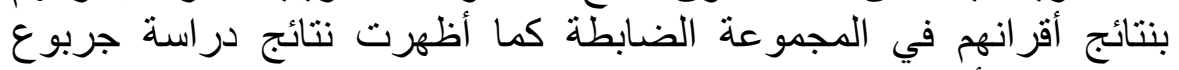

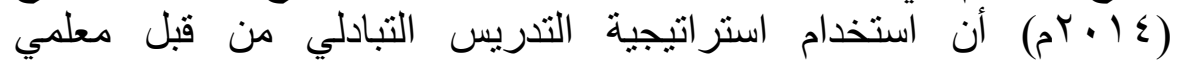

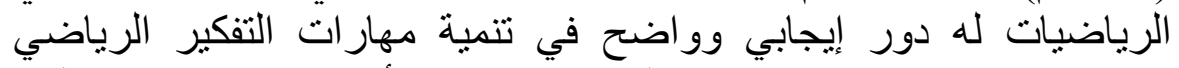

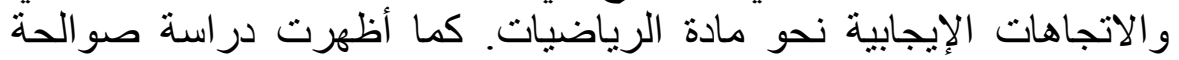

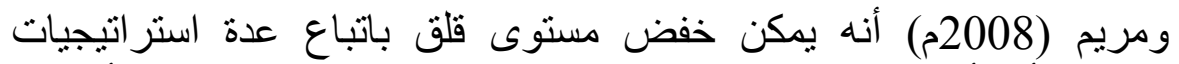

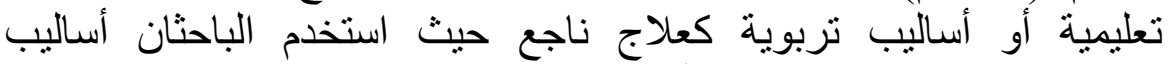

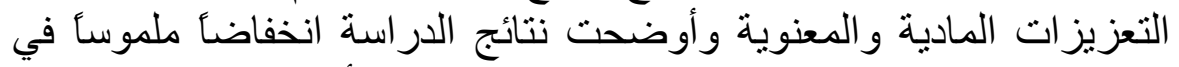
مستوى قلق الرياضيات لدى الطلاب. و الجدير بالذكر أن استخدام استراتية التيجية

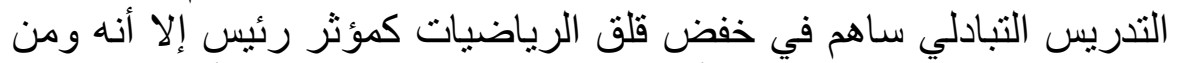

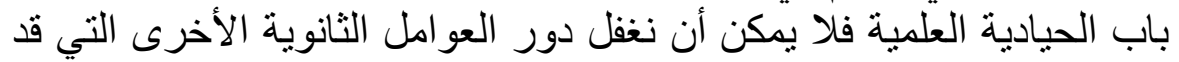

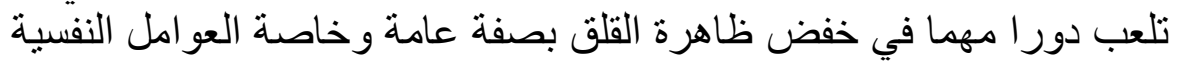
مثل ألفة الطالب مع المفاهيم والمهارات الرياضية أثناء التدريس، شخدية شئية

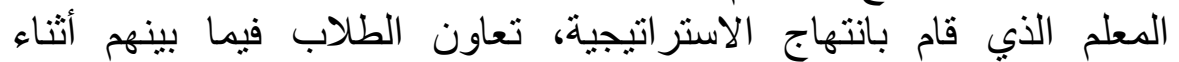

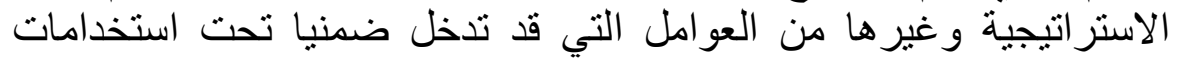

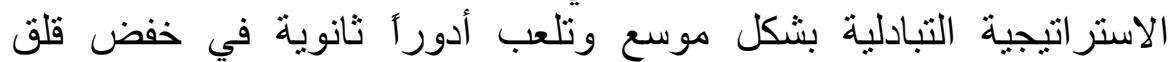

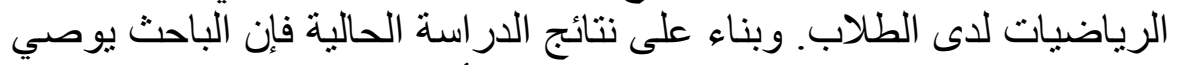

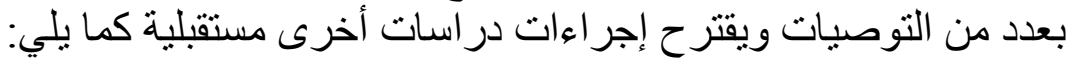

\section{سادساً: توصيات الدراسة:}

\section{بناء على نتائج الدراسة الحالية يمكن التوصية بما يلي:}

1 ـ تحديد عدد الطلاب المعلمين الذين يعانون من ظاهرة قلق رياضيات

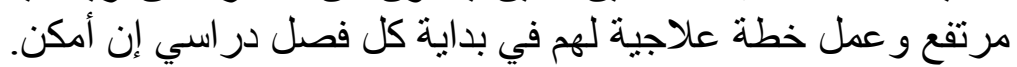

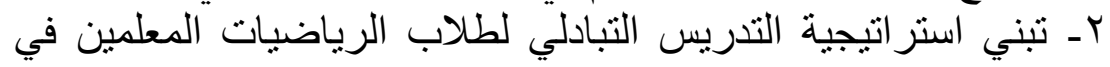

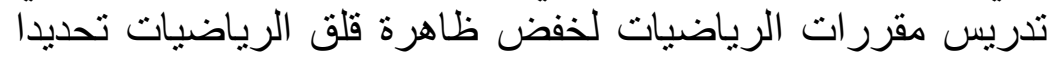
و غير ها من المقرر ات العلمية المشابهة. 
rـ تطوير منهج مقرر طرق تدريس الرياضيات وفق استراتيجية

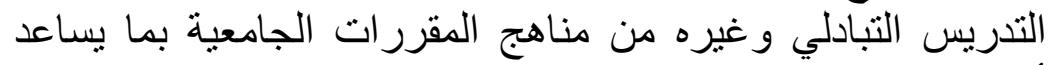

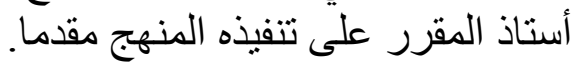

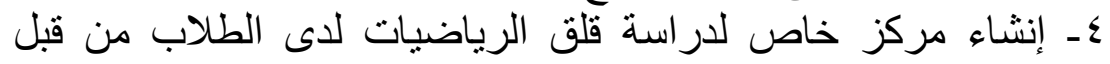

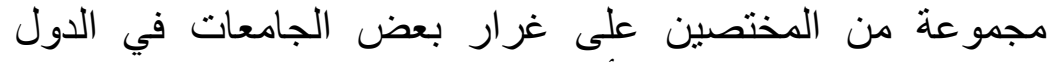
المتقدمة (الو لايات المتحدة الأمريكية). هـ تدريب معلمي الرياضيات في مختلف المر احل الدر اسية على تلفيذ التهيذ استر اتيجية التدريس التبادلي مع طلابهر. سابعاً: مقترحاث لار اسات مستقبلية: بناء على نتائج الدراسة الحالية يقترح إجراء الدراسات التالية:

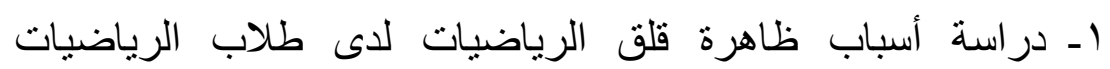

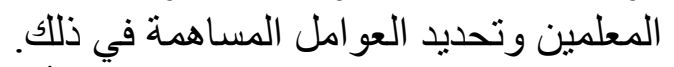
r- بحث وإيجاد استراتيجيات تدريسية أخرى مشابهة أو أو مغايره

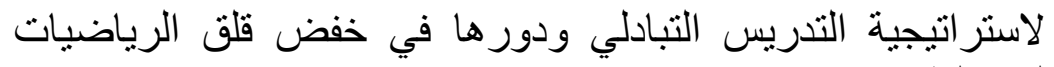
لاعى الطلاب. rـ إجر اء در اسات مماثلة على جنس الاناث في المستوى الجامعي حيث

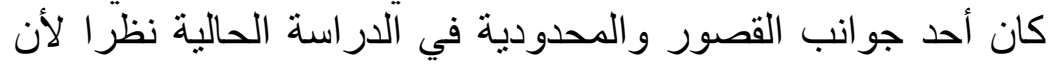
نظام التعليم السعودي يمنع الاختلاط.

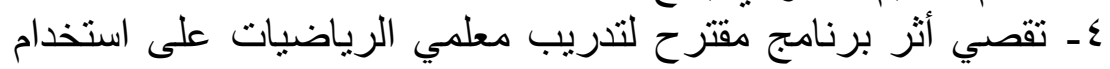
استر اتيجية التدريس التبادلي في دروس الرئري لتريبات مع طلابهم. 


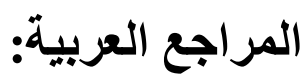

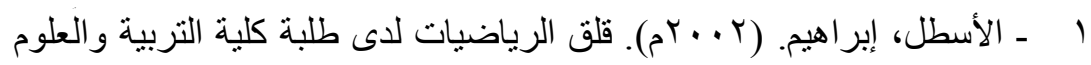

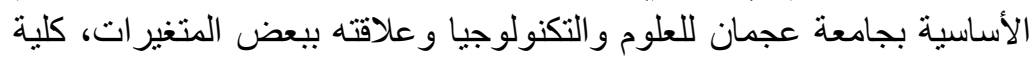

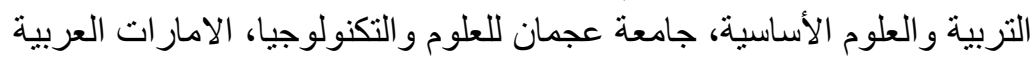

المتحدة.

http://www.alaqsa.edu.ps/site resources/aqsa magazine $. \mathrm{pdf} \leqslant 9 /$ files/

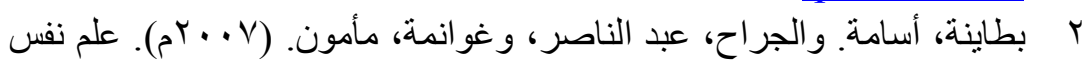

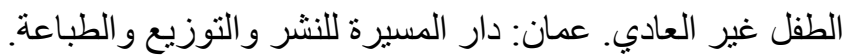

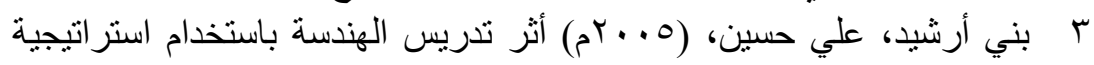

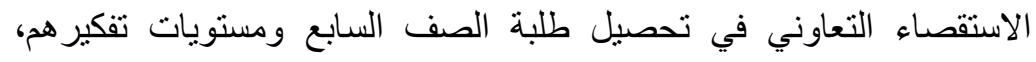

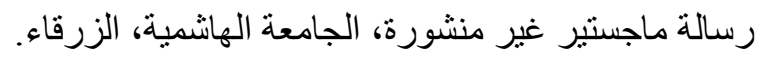

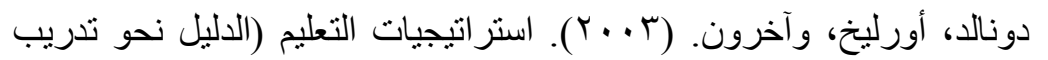

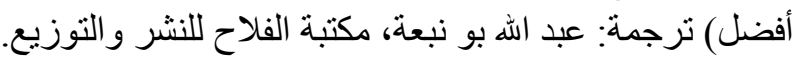

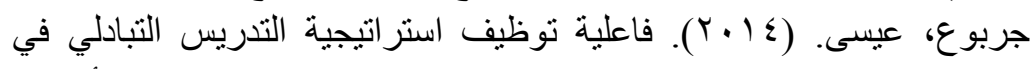

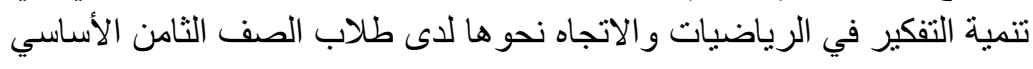
بغزة،

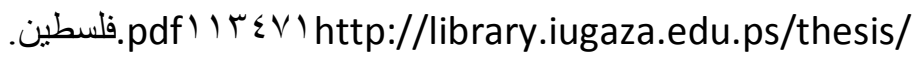

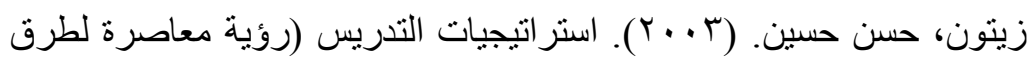
1

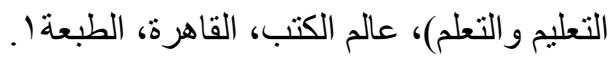

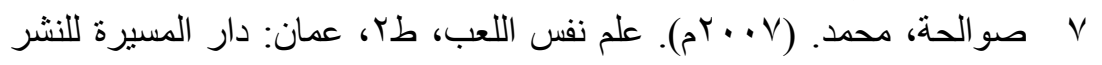
و التوزيع و الطباعة

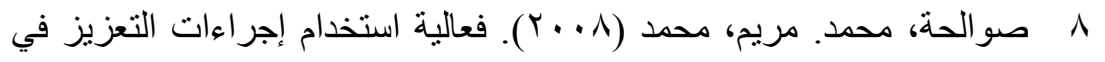

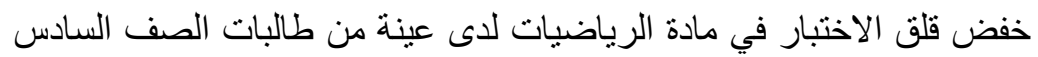

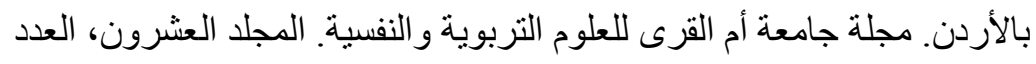

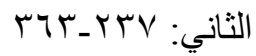

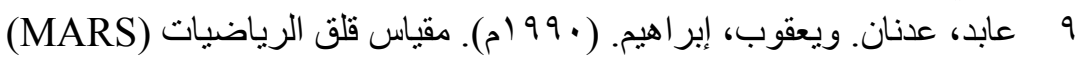

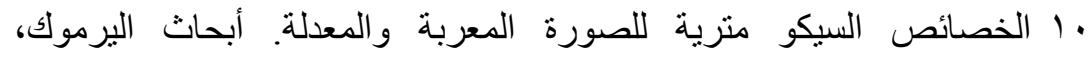
. $1 \leqslant \varepsilon-11 r:(\varepsilon)^{\top}$ 


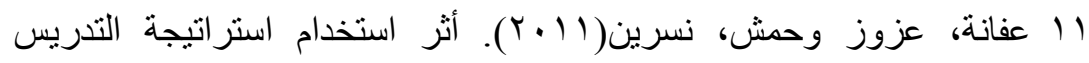

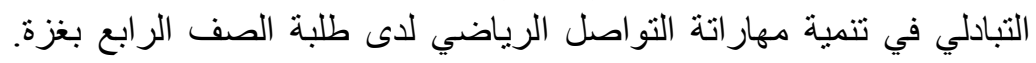

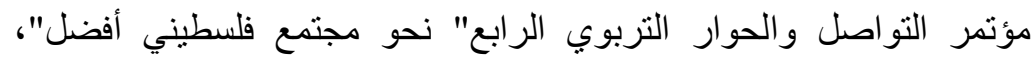

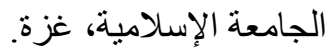

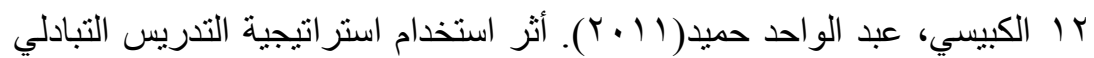

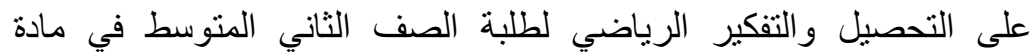

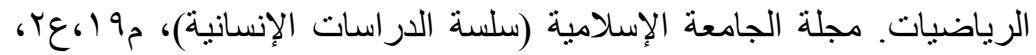
ص VMVINV

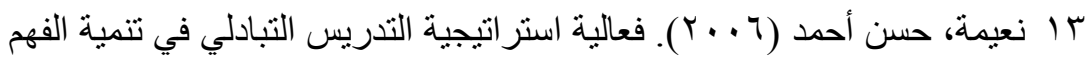

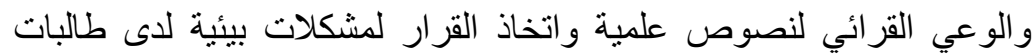

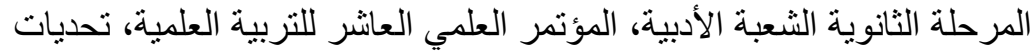

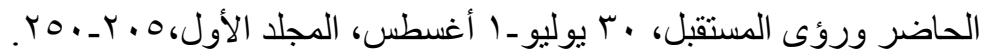

\section{English References}

14 - Al Zahrani, Yahya (2014). Curriculum Evaluation of the Mathematics Pedagogy Module for Undergraduate Preservice Primary Mathematics Teachers at University Level. Unpublished PhD thesis, Southampton University, United Kingdom.

151 - 15 Al-Ghamdi, S., Al-Gaied, A. and Abu-rasain, M. (2010) Faculty evaluation in Saudi Arabia: A suggested model (in Arabic). Riyadh: Research and Studies Centre in Higher Education.

16 10- Ashcraft, M. H. (2002). Math anxiety: personal, educational, and cogntive consequences. Current Directions in Psycholoical Science, 11, 181-185.

17 16- Bakare, T.V. (2011) The use of teaching methods and styles in the Nigerian university system: The curriculum and policy implications for change. Journal of International Education, 7(1): 89-98.

18 17- Ball, D.L., and Bass, H. (2003) Toward a practice-based theory of mathematical knowledge for teaching. Paper 


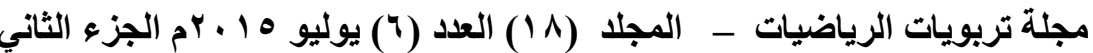

presented at the Proceedings of the 2002 annual meeting of the Canadian Mathematics Education Study Group, Edmonton, $\mathrm{AB}$.

19 18- Carroll, C. (2003) Developing Math Confidence. University of Florida Counselling Centre. (online) : available:

http://www.counsel.ufl.edu/selfHelp/mathConfidence.asp

20 Chewning, S.(2002) Overcoming math anxiety. Germanna community College. (on line): Available:

21 19- Emekli, G., S., (2002): Effects of Epistemological Beliefs and Reciprocal Teaching and social Learning on Minority Secondary Students Attitudes Toward Since, Dissertaion Abstracts International, Vol.63-05 A, P.1687.

22 20- Lori, D. (2003). Reciprocal teaching at work: Strategies For Improving reading comprehension, (on line). http:// marketplace: reading org, / products/ tnt products. Cfm. Subsystem \& Product class \& I rebook action long.

23 21- Nadine, S. (2009). Improving students' reading comprehension skills: Effects of strategy instruction and reciprocal, in learning and instruction volume 19. Issue 3. June 2009. Pages 272-286.

24 22- Sloan, T. R.(2000) Mathematics Anxiety: Causes and Treatments. School of Education. Athen State University. (on line):

Available:

http://home.hiwaay.net/ kenth/diane/column/p_040500.h $\underline{\mathrm{tm}}$.

25 23- Smith, L. and Abouammoh, xxx. (Eds), (2013) Higher education in Saudi Arabia: Achievments, challenges and opportunities. Heidelberg, New York, London:Springer Dordrecht.

26 24- Tatto, M.T., Ingvarson, L., Schwille, J., Peck, R., Senk, S.L. and Rowly,G.(2010) the organization of the mathematics preparation and development of teachers: a report from the 


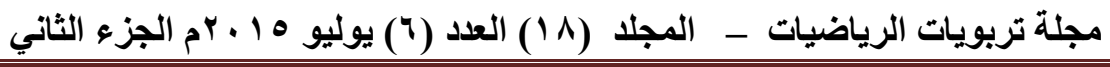

ICMI Study 15, Journal of Mathematics Teacher Education, 112.

27 25- Walsh, K. A (2008). The relationship among mathematics anxiety, beliefs about mathematics, mathematics self-efficacy, and mathematics. performance in associate degree nursing students. Nursing education perspectives, 29,226-229. 